\title{
Modeling and design guidelines for direct steam generation solar receivers
}

\author{
Meng Lin ${ }^{\mathrm{a}}$, Jan Reinhold ${ }^{\mathrm{b}}$, Nathalie Monnerie ${ }^{\mathrm{b}}$, Sophia Haussener ${ }^{\mathrm{a}, *}$ \\ a Laboratory of Renewable Energy Science and Engineering, EPFL, Station 9, 1015 Lausanne, Switzerland \\ ${ }^{\mathrm{b}}$ German Aerospace Center (DLR), Linder Hoehe, 51147 Koeln, Germany
}

\section{H I G H L I G H T S}

- A computational model for solar receiver for direct steam generation is developed.

- Experiments are conducted and used to validate the model.

- Practical designs, operational conditions and material choices are investigated.

- Model provides design tool for direct steam generation solar cavity receivers.

\section{A R T I C L E I N F O}

\section{Keyword:}

Solar energy

Multi-mode heat transfer modeling

Two-phase flow modeling

Solar receiver

Steam generator

Concentrated solar

\begin{abstract}
A B S T R A C T
Concentrated solar energy is an ideal energy source for high-temperature energy conversion processes such as concentrated solar power generation, solar thermochemical fuel production, and solar driven high-temperature electrolysis. Indirectly irradiated solar receiver designs utilizing tubular absorbers enclosed by a cavity are possible candidates for direct steam generation, allowing for design flexibility and high efficiency. We developed a coupled heat and mass transfer model of cavity receivers with tubular absorbers to guide the design of solardriven direct steam generation. The numerical model consisted of a detailed 1D two-phase flow model of the absorber tubes coupled to a 3D heat transfer model of the cavity receiver. The absorber tube model simulated the flow boiling phenomena inside the tubes by solving 1D continuity, momentum, and energy conservation equations based on a control volume formulation. The Thome-El Hajal flow pattern maps were used to predict liquid-gas distributions in the tubular cross-sections, and heat transfer coefficients and pressure drop along the tubes. The heat transfer coefficient and fluid temperature of the absorber tubes' inner surfaces were then extrapolated to the circumferential of the tube and used in the 3D cavity receiver model. The 3D steady state model of the cavity receiver coupled radiative, convective, and conductive heat transfer. The complete model was validated with experimental data and used to analyze different receiver types and designs made of different materials and exposed to various operational conditions. The proposed numerical model and the obtained results provide an engineering design tool for cavity receivers with tubular absorbers (in terms of tube shapes, tube diameter, and water-cooled front), support the choice of best-performant operation (in terms of radiative flux, mass flow rate, and pressure), and aid in the choice of the component materials. The model allows for an indepth understanding of the coupled heat and mass transfer in the solar receiver for direct steam generation and can be exploited to quantify the optimization potential of such solar receivers.
\end{abstract}

\section{Introduction}

Concentrated solar technologies offer promising opportunities for efficient solar-driven power generation systems (e.g., concentrated solar power (CSP) [1-5], solar thermochemical fuel production (STFP) [6-10], or solar driven high-temperature electrolysis (SHTE) [11]). The solar receiver is a key component in these applications converting solar energy efficiently into thermal energy. Numerical models offer an effective pathway for the characterization and quantification of the optical, thermal, and fluid flow behavior of receivers [12-18]. When steam is used as the working fluid (CSP application) or as the reactant in high-temperature systems (STEP and SHTE applications), the understanding of the complex two-phase flow boiling process inside the absorber tubes of the direct steam generation receiver is important for identifying local hot spots, and designing and predicting receiver performance. The modeling approach for the coupled heat transfer and fluid flow problem in direct steam generation solar receivers can be inspired by the design of conventional steam generators or evaporators

\footnotetext{
* Corresponding author.

E-mail address: sophia.haussener@epfl.ch (S. Haussener).
} 


\begin{tabular}{|c|c|c|c|}
\hline \multirow{2}{*}{\multicolumn{2}{|c|}{ Nomenclature }} & $\delta$ & standard deviation $(\mathrm{m})$ \\
\hline & & $\delta_{i j}$ & visibility \\
\hline \multirow{2}{*}{\multicolumn{2}{|c|}{ Latin symbols }} & $\delta_{\mathrm{lf}}$ & liquid film thickness (m) \\
\hline & & $\varepsilon_{\mathrm{g}}$ & void fraction \\
\hline$A$ & area $\left(\mathrm{m}^{2}\right)$ & $\nu^{\circ}$ & kinematic viscosity $\left(\mathrm{m}^{2} / \mathrm{s}\right)$ \\
\hline$a$ & thermal diffusivity $\left(\mathrm{m}^{2} / \mathrm{s}\right)$ & $\xi_{\mathrm{ph}}$ & liquid-vapor interfacial friction factor \\
\hline$c_{\mathrm{p}}$ & heat capacity (W/kg/K) & $\rho$ & density $\left(\mathrm{kg} / \mathrm{m}^{3}\right)$ \\
\hline$d$ & diameter $(\mathrm{m})$ & $\sigma$ & Stefan-Boltzmann constant $\left(5.67 \mathrm{e}^{8} \mathrm{~W} / \mathrm{m}^{2} / \mathrm{K}\right)$ \\
\hline E & two-phase convection multiplier & $\sigma_{\mathrm{t}}$ & surface tension $(\mathrm{N} / \mathrm{m})$ \\
\hline$F$ & view factor & $\eta_{\mathrm{STT}}$ & solar-to-thermal efficiency \\
\hline $\mathrm{Fr}$ & Froude number & $\theta$ & tube inclination angle (rad) \\
\hline$f$ & friction factor & $\theta_{\text {dry }}$ & dry angle (rad) \\
\hline$g$ & acceleration of gravity $\left(\mathrm{m} / \mathrm{s}^{2}\right)$ & $\theta_{\text {strat }}$ & stratified angle (rad) \\
\hline$H$ & height (m) & $\mu$ & dynamic viscosity (Pa s) \\
\hline$h$ & heat transfer coefficient $\left(\mathrm{W} / \mathrm{m}^{2} / \mathrm{K}\right)$ & $\tau_{\mathrm{w}}$ & shear stress $(\mathrm{Pa})$ \\
\hline $\bar{h}$ & averaged heat transfer coefficient $\left(\mathrm{W} / \mathrm{m}^{2} / \mathrm{K}\right)$ & $\varphi$ & receiver tilt angle (rad) \\
\hline$h_{\mathrm{g}}$ & enthalpy for gas $(\mathrm{kJ} / \mathrm{kg} / \mathrm{K})$ & & \\
\hline$h_{\lg }$ & latent heat $(\mathrm{kJ} / \mathrm{kg})$ & \multirow{2}{*}{\multicolumn{2}{|c|}{ Subscripts }} \\
\hline$h_{1}$ & enthalpy for liquid ( $\mathrm{kJ} / \mathrm{kg} / \mathrm{K})$ & & \\
\hline$J$ & radiosity $(\mathrm{W})$ & $\mathrm{amb}$ & ambient \\
\hline$k$ & thermal conductivity $(\mathrm{W} / \mathrm{m} / \mathrm{K})$ & ap & aperture \\
\hline$L$ & length $(\mathrm{m})$ & $\mathrm{cb}$ & convective boiling \\
\hline$\dot{m}$ & mass flow rate $(\mathrm{kg} / \mathrm{s})$ & cav & cavity \\
\hline$\dot{m}^{\prime \prime}$ & mass flux $\left(\mathrm{kg} / \mathrm{m}^{2} / \mathrm{s}\right)$ & cond & conduction \\
\hline $\mathrm{Nu}$ & Nusselt number & conv & convection \\
\hline$P$ & tube perimeter $(\mathrm{m})$ & crit & critical value \\
\hline $\operatorname{Pr}$ & Prandtl number & DNB & departure from nucleate boiling \\
\hline$p$ & pressure $(\mathrm{Pa})$ & dry & dry-out \\
\hline$p_{\mathrm{r}}$ & reduced pressure & $\mathrm{g}$ & gas phase \\
\hline$\dot{Q}$ & heat rate $(\mathrm{W})$ & in & inner \\
\hline$q^{\prime \prime \prime \prime}$ & heat sink $\left(\mathrm{W} / \mathrm{m}^{3}\right)$ & IA & intermittent flow to annular flow \\
\hline$q_{\mathrm{w}}$ & heat flux $\left(\mathrm{W} / \mathrm{m}^{2}\right)$ & $i, j$ & location index \\
\hline$R a$ & Rayleigh number & insu & insulation material \\
\hline$r_{i j}$ & distance $(\mathrm{m})$ & 1 & liquid phase \\
\hline$r_{\text {turn }}$ & helical turning radius (m) & $\max$ & maximum value \\
\hline$S$ & boiling suppression factor & $\min$ & minimum value \\
\hline$T$ & temperature $(\mathrm{K})$ & mist & mist flow \\
\hline $\bar{T}$ & averaged temperature $(\mathrm{K})$ & $\mathrm{nb}$ & nucleate boiling \\
\hline$t_{\mathrm{wall}}$ & thin wall thickness (m) & nc & natural convection \\
\hline$v$ & velocity $(\mathrm{m} / \mathrm{s})$ & rerad & reradiation \\
\hline$W e$ & Weber number & strat & stratified flow \\
\hline$x_{\mathrm{g}}$ & vapor quality & wavy & stratified-wavy flow \\
\hline \multicolumn{4}{|c|}{ Greek } \\
\hline$\beta$ & thermal expansion coefficient $(1 / \mathrm{K})$ & & \\
\hline
\end{tabular}

in coal-fired boiler power plants $[19,20]$, pressurized water reactors (PWR) in nuclear power plants [21-23], and vapor-compression refrigeration system $[24,25]$. The development of a full 3D mechanistic model of the flow boiling process is challenging [26] due to the complex nature of the processes involved (activation of nucleation sites, bubble dynamics, and interfacial heat transfers) and the computational needs required for the solution of the direct numerical problem, which incorporates a large number of bubbles and surfaces with complex geometries $[27,28]$. To overcome this challenge, semi-mechanistic approaches are proposed [29-34]. For example, Kurul and Podowski developed a 3D model which couples an Euler-Euler two-phase flow model (for bulk fluid flow) with a wall boiling model. The wall boiling model partitioned the heat flux between the tube wall and the fluid into three parts: liquid phase convective heat flux, quenching heat flux, and evaporation heat flux (wall boiling phenomena), predicting each heat flux by empirical and mechanistic correlations. Due to the numerical instability and large computational cost of the wall boiling model, a bulk boiling model was used instead and coupled with an Euler-Euler two-phase flow model in the modeling of a PWR nuclear steam generator [21]. The bulk boiling model agreed well with the experimental data. In the engineering design of evaporators and steam generators, the wall-fluid heat transfer is more important in determining the thermal performance than the detailed in-tube liquid-vapor interfacial heat and mass transfer. Hence less computationally expensive 1D twofluid (separated or homogeneous) two-phase flow models with empirical correlations (single equation correlations [35,36] and flow pattern based correlations $[37,38]$ ) for the wall-fluid heat transfer coefficients are commonly employed [39-41] without resolving the local non-uniformity of the wall-liquid heat transfer. An obvious disadvantage of a simplified 1D two-phase model with empirical correlations is that the local heat transfer and temperature distribution cannot be accurately captured. However, this might be extremely important for the determination of the critical point. Oliet et al. [24] proposed an integrated model for a fin-and-tube evaporator by linking a fin-and-tube 
solid core 2D heat transfer model and an 1D in-tube separated twophase flow model. They showed accurate and computationally cost effective predictions for fin-and-tube local temperature distributions, based on calculated non-uniform wall-fluid heat transfer coefficients captured by using advanced flow pattern maps based on wall wetting conditions for different flow regimes [42].

The modeling efforts for solar-driven tubular cavity receivers and reactors have been extensively reported [16,43-47]. Martinek et al. $[16,44]$ developed a 3D steady-state model for a multi-tubular solar reactor for steam gasification of carbon using a hybrid Monte Carlo/ Finite Volume method for radiative heat transfer and a single-phase fluid flow model with volume-averaged mixture properties. However, 3D models cannot be directly used for accurate modeling of a tubular cavity solar receiver for direct steam generation since the 3D direct numerical simulation of two-phase boiling flow is difficult and computational expensive.

We used inspiration of the two-phase flow modeling methods for conventional steam generatorsand evaporators, and of the multi-mode heat transfer modeling in the solar receiver modeling community to develop a solar receiver model for direct steam generation considering the in-tube two-phase flow phenomena. The approach is the following: a 1D two-phase flow model for the in-tube two-phase flow is coupled to a 3D heat transfer model of the receiver cavity, providing a simplified but accurate and computationally efficient model. A similar approach has been used by Zapata et al. [48], one of the view reported modeling studies for solar-driven steam generation $[46,48,49]$. They used a 3D multi-mode heat transfer receiver model, however, they solved only a homogenous two-phase 1D model inside the absorber tube utilizing empirical correlations to predict the heat transfer between the tube surface and the working fluid without resolving the circumferential variations in the heat transfer coefficient. However, the non-uniform heat transfer together with the non-uniform solar irradiation will potentially lead to large temperature gradients in the absorber tube and is responsible for hot spots. Circumferentially resolved heat transfer is required to accurately identify hot spots. Here, we paid specially attention to hot spots induced by the dryout of the in-tube two-phase flow where the temperature gradients are large (temperature jump between two mesh elements larger than $100 \mathrm{~K}$ ) and therefore worked with a method that allows for the resolution of the non-uniform heat transfer, also in the circumferential direction of the tube.

We utilize a 1D two-phase flow absorber tube model and couple it to flow pattern maps to accurately account for and extrapolate for the circumferentially varying heat transfer behavior in the tube. The schematic of the two types of receivers investigated and the calculation domains (consisting of insulation, cavity, and tubes) are shown in Fig. 1. The heat transfer and fluid flow inside the absorber tubes are analyzed by a separated 1D two-phase flow model considering continuity, energy, and momentum equations (the conservation equations are solved for the combined flow while the velocities are different for the two phases [50]) to calculate the fluid temperature, phase velocity, liquid-vapor velocity slip, and heat transfer coefficient in the absorber tubes based on the absorbed radiation calculated from the 3D heat transfer model in the cavity. The fluid temperature and the heat transfer coefficient obtained by the 1D two-phase flow model are then extrapolated to a 3D temperature and heat transfer coefficient profile utilizing two-phase flow pattern maps. The obtained temperature and heat transfer coefficient at the inner absorber tube provide a convective boundary condition to the heat transfer model in the cavity.

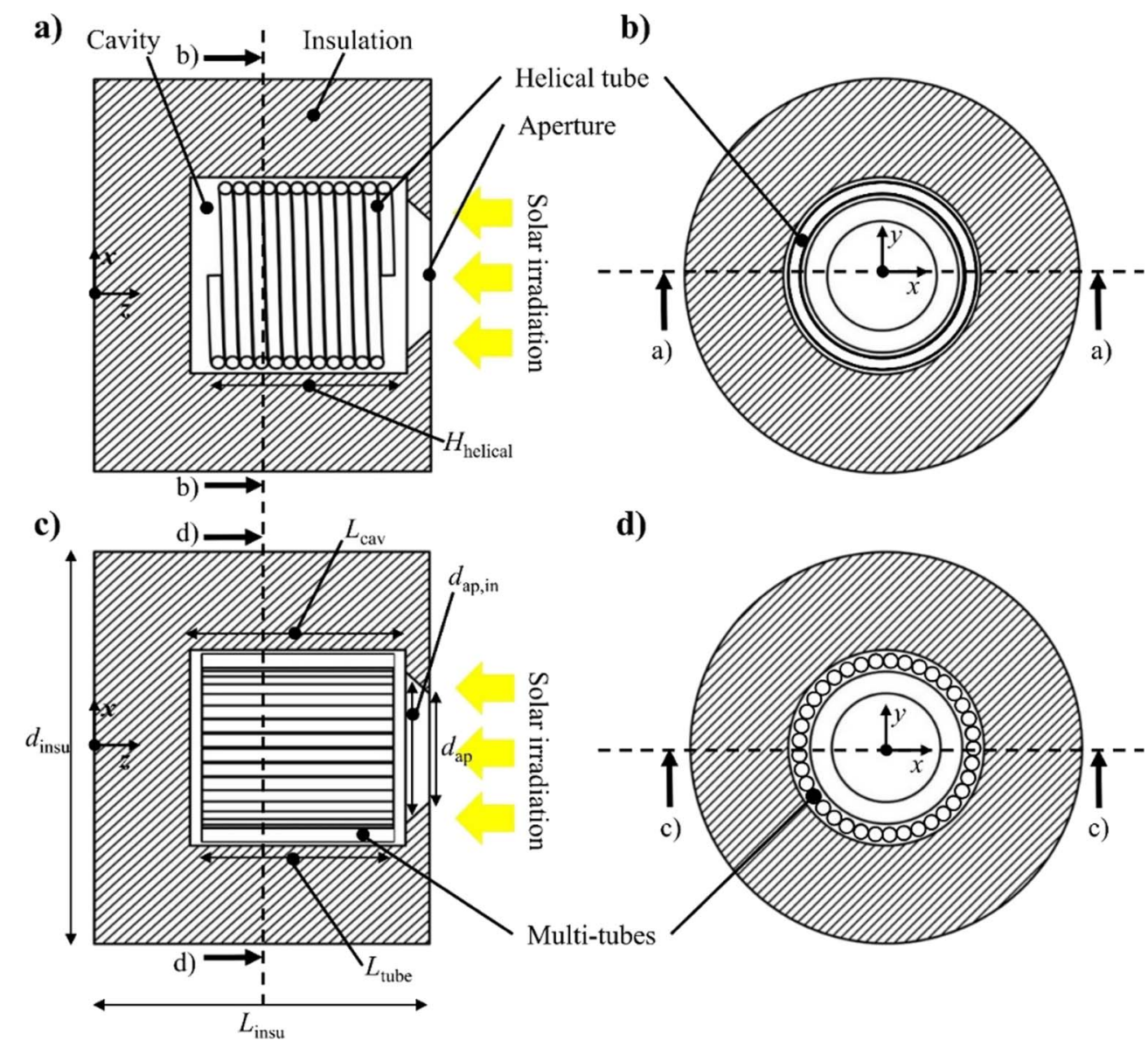

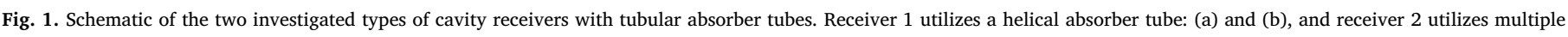
connected straight absorber tubes: (c) and (d). 


\section{Model development}

\subsection{Cavity model}

\subsubsection{Radiation model}

The spatial distribution of the solar irradiation magnitude at the aperture of the cavity was approximated by a Gaussian distribution [51]. We assumed the angular distribution to be diffuse. This assumption was made in order to ensure a broader applicability of the results as the angular distribution of concentrating solar facilities is highly dependent on the design of the primary concentrator and position of the receiver.

The receiver aperture boundary was treated as a high-temperature black body emitting into the receiver at an equivalent temperature described by:

$T_{i}^{\mathrm{eff}}=\left(\frac{q_{\mathrm{solar}, i}+\sigma T_{\mathrm{amb}}^{4}}{\sigma}\right)^{\frac{1}{4}}$,

$q_{\text {solar }, i}=q_{\text {peak }} \exp \left(-\frac{\left(x_{i}-x_{0}\right)^{2}}{2 \delta_{x}}-\frac{\left(y_{i}-y_{0}\right)^{2}}{2 \delta_{y}}\right)$,

where $T_{i}^{\text {eff }}$ is the effective temperature for surface element $i$ at the aperture, $\delta_{x}$ and $\delta_{y}$ are the standard deviations of the Gaussian flux approximation for the $x$ - and $y$-axis (equal in our case as the profile is symmetric), $x_{i}$ and $y_{i}$ are the location at the aperture, $x_{0}$ and $y_{0}$ are the coordinates of the aperture center, $q_{\text {solar } i}$ is the local solar irradiation at the aperture surface element $i, q_{\text {peak }}$ is the peak flux density, and $\sigma$ is the Stefan-Boltzmann constant. Fig. S1 shows the sensitivity of the results with respect to the exact choice of $\delta_{x}$, indicating that the impact of $\delta_{x}$ on the thermal performance of both receiver types (receiver 1 and 2) is negligible.

The surfaces inside the receiver cavity were assumed grey and diffuse, and the air inside the cavity was treated as a radiatively nonparticipating medium. The heat conduction and fluid flow inside the cavity was not numerically computed. Instead a surface heat sink was used with a semi-empirical heat transfer coefficient (see Section 2.1.2). The radiative heat transfer within the receiver cavity was described by a surface-to-surface radiation model,

$J_{i}=E_{i}+\rho_{i} \sum_{j=1}^{N} F_{i j} J_{j}$,

$F_{i j}=\frac{1}{A_{i}} \int_{A_{i}} \int_{A_{j}} \frac{\cos \theta_{i} \cos \theta_{j}}{\pi r_{i j}^{2}} \delta_{i j} \mathrm{~d} A_{i} \mathrm{~d} A_{j}$,

where $J_{i}$ represents the radiosity of surface $i, E_{i}$ is the emissive power, $N$ is the total number of surfaces, $F_{i j}$ is the view factor between surfaces $i$ and $j, A$ is the surface area, $r_{i j}$ is the distance between two area-centroids of two surfaces, $\theta$ is the angle between the surface normal and the vector connecting area centers $i$ and $j$, and $\delta_{i j}$ is a dirac function determined by the visibility of surface $i$ and $j\left(\delta_{i j}=1\right.$ if $\mathrm{d} A_{j}$ is visible to $\mathrm{d} A_{i}$ and 0 otherwise). The radiative heat transfer model was applied to all inner cavity surfaces and the aperture. The re-radiation loss, $\dot{Q}_{\text {rerad, }}$ was defined as the total emitted power from the inner cavity surfaces toward the aperture.

\subsubsection{Natural convection model}

The convective heat loss through the cavity receiver aperture was quantified by utilizing an empirical correlation. This correlation is based on 3D numerical heat and flow simulations adjusted by considering experimentally measured heat transfer rates reported in [52]. The total natural convection heat loss from the aperture was given as:

$\dot{Q}_{\mathrm{nc}}=A_{\mathrm{cav}, \text { in }} h_{\mathrm{nc}}\left(\bar{T}_{\mathrm{cav}, \mathrm{in}}-T_{\mathrm{amb}}\right)$,

$N u_{L}=0.0196 \operatorname{Ra}_{L}^{0.41} \operatorname{Pr}^{0.13}$,
$L=\left|\sum_{i=1}^{3} a_{i} \cos \left(\phi+\varphi_{i}\right)^{b_{i}} L_{i}\right|$

where $A_{\text {cav,in }}$ is the total inner surface area of the receiver cavity, the Rayleigh number is given by $R a_{L}=\frac{g \beta\left(\bar{T}_{\text {cav }, \text { in }}-T_{\text {amb }}\right) L^{3}}{\nu \alpha}$ [53], and $L$ is the ensemble length. $L$ was calculated using the cavity receiver tilt angle $\phi$ (considered to be $0^{\circ}$ in this study), the cavity inner diameter $L_{1}$, the cavity depth $L_{2}$, the cavity open aperture diameter $L_{3}$, and the fitting coefficients $a_{\mathrm{i}}, b_{\mathrm{i}}$, and $\varphi_{i}$ (the schematic representation of the cavity and the coefficients' values are given in ref [52]). $\bar{T}_{\text {cav,in }}$ is the average temperature of the cavity's inner surfaces, including the absorber tubes' surfaces. An averaged heat transfer coefficient, $\bar{h}_{\mathrm{nc}}$, of the absorber tube surfaces was defined in order to estimate the local cooling effect by natural convection:

$\bar{h}_{\mathrm{nc}}=\frac{\dot{Q}_{\mathrm{nc}}}{A_{\text {tube }}\left(\bar{T}_{\text {tube }}-T_{\mathrm{amb}}\right)}$,

where $A_{\text {tube }}$ is the total absorber tube area, and $\bar{T}_{\text {tube }}$ is the tube surfaceaveraged temperature. A boundary heat sink term was calculated and applied to the tube surfaces using a thin wall conduction model $\left(t_{\text {wall }}\right.$ was $10^{-6} \mathrm{~m}$, the results were not sensitive to $t_{\text {wall }}$, see Fig. S2):

$q^{\prime \prime \prime}$ nc,sink $=-\bar{h}_{\mathrm{nc}}\left(T_{i, \text { tube }}-T_{\mathrm{amb}}\right) / t_{\mathrm{wall}}$.

The convective heat loss, $\dot{Q}_{\text {conv }}$, was the integration of the heat sink term over the tubes' thin walls and was - by definition - equals to $\dot{Q}_{\mathrm{nc}}$. This correlation-based natural convection model can reasonably well predict the overall heat losses due to natural convection at a low computational cost as there is no need for a numerical solution of the heat transfer and fluid flow within the cavity inner and ambient air domains $[44,45]$. However, this global approach can lead to inaccuracies in predicting the local flux as the local natural convection heat flux is only a function of the local surface temperature, neglecting any effects from locally present flow zones (main flow, stagnant zone, and the couterflow zone [54]). This may lead to inaccuracy in predicting the local surface temperature which in turn leads to inaccuracy in predicting the hot spots. However, the dominating effect for hot spots is the sharp decrease in the in-tube wall-fluid heat transfer coefficient while the natural convection heat transfer coefficient played only a minor role. For example, the heat transfer coefficient reduced from $\sim 11,000 \mathrm{~W} / \mathrm{m}^{2} / \mathrm{K}$ to $\sim 1000 \mathrm{~W} / \mathrm{m}^{2} / \mathrm{K}$ at the dryout point for the receiver 1 at the reference condition, while the predicted natural convection heat transfer coefficient was only $\sim 4 \mathrm{~W} / \mathrm{m}^{2} / \mathrm{K}$.

\subsubsection{Conduction}

The energy conservation for the solid domains of the receiver (insulation and tubes' walls) was described by,

$\nabla \cdot(k \nabla T)=0$,

where $k$ is the thermal conductivity of the solid material. The boundary condition for the tubes' outer surfaces was the net surface energy flux by natural convection and radiation. The inner tubes' surface boundary condition was set as the convection boundary, coupling the 3D receiver model to the 1D tube model (see Section 2.2). A combined radiation and convection boundary condition was applied at the outer surfaces of the insulation with the ambient temperature equals to $298 \mathrm{~K}$, surface emissivity of 0.8 , and heat transfer coefficient of $5 \mathrm{~W} / \mathrm{m}^{2} / \mathrm{K}$ (a reasonable estimation for natural convection from external cavity walls [55]). The conductive heat loss, $\dot{Q}_{\text {cond }}$, was the total heat transfer from the cavity inner surface wall to the outer surface wall trough conduction.

\subsection{Tube model}

\subsubsection{Two-phase flow model inside tubes}

The two-phase flow was modeled by a steady state 1D separated two-phase flow model $[39,50]$ which assumed the same pressure and temperature in each phase at any cross section of the tube while 
allowing for a slip velocity between the liquid and vapor phases. Compared to a homogenous flow model, a separated flow model can capture - while simple in formulation - more accurately the physical flow behavior with each phase having different properties and velocities. A two fluids model could alternatively be used to predict more precisely the flow behavior by separately solving the conservation equations for two phases without the need for empirical correlations for the prediction of the void fraction. However, at the expense of significant computational costs and potentially numerical instability. Here, we chose the separated flow model as a good comprise between computational cost and model accuracy. The two-phase continuity equation,

$\frac{\mathrm{d}}{\mathrm{d} z}\left[\rho_{\mathrm{g}} v_{\mathrm{g}} \varepsilon_{\mathrm{g}}+\rho_{\mathrm{l}} v_{\mathrm{l}}\left(1-\varepsilon_{\mathrm{g}}\right)\right]=0$,

was solved, where $\rho_{\mathrm{g}}$ and $\rho_{1}$ are the density of the gas and liquid phases, $v_{\mathrm{g}}$ and $v_{1}$ are the velocities, and $\varepsilon_{\mathrm{g}}$ is the void fraction of the gas phase. The momentum equation,

$-\frac{\mathrm{d} p}{\mathrm{~d} z}=\frac{\mathrm{d}}{\mathrm{d} z}\left[\rho_{\mathrm{g}} v_{\mathrm{g}}^{2} \varepsilon_{\mathrm{g}}+\rho_{1} v_{\mathrm{l}}^{2}\left(1-\varepsilon_{\mathrm{g}}\right)\right]+g \rho \cos \theta+\frac{\tau_{w} P}{A_{\text {tube,in }}}$,

was solved, where $p$ is the pressure, $\rho=\left(1-\varepsilon_{\mathrm{g}}\right) \rho_{1}+\varepsilon_{\mathrm{g}} \rho_{\mathrm{g}}$ is the volumeaveraged density, $P$ is the tubes' inner circumferences, $A_{\text {tube,in }}=\pi d_{\text {tube,in }}^{2} / 4$ is the cross sectional area of tube, $\tau_{w}=(f / 4)\left(\dot{m}^{2} / 2 \rho A_{\text {tube,cross }}^{2}\right)$ is the wall shear stress, and $\theta$ is the inclination angle of the tube. $\theta$ was determined locally for each tube segment according to the tube orientation. The first term on the right side of Eq. (12) is the momentum pressure drop, the second term represents the static pressure change, and the third term is the frictional pressure drop. The friction factor, $f$, was estimated by empirical correlations. In the single phase flow region, $f$ was predicted by the Blasius equation [35]. In the two-phase flow region, $f$ was predicted by the Friedel correction [56], implemented by utilizing a two-phase multiplier on the liquid phase friction factor.

The energy equation,

$$
\begin{aligned}
& \frac{\mathrm{d}}{\mathrm{d} z}\left[\rho_{\mathrm{g}} v_{\mathrm{g}} \varepsilon_{\mathrm{g}}\left(h_{\mathrm{g}}+\frac{v_{\mathrm{g}}^{2}}{2}+g z \cos \theta\right)+\rho_{\mathrm{l}} v_{1}\left(1-\varepsilon_{\mathrm{g}}\right)\left(h_{1}+\frac{v_{\mathrm{l}}^{2}}{2}+g z \cos \theta\right)\right] \\
& \quad=\frac{P q_{\mathrm{w}}}{A_{\text {tube, in }}},
\end{aligned}
$$

was solved, where $h_{\mathrm{g}}$ and $h_{1}$ are the enthalpy of gas and liquid phases evaluated based on local temperature and pressure, and $q_{\mathrm{w}}$ is the heat flux at the tube inner wall which was obtained by the calculation of a surface-averaged heat flux obtained from the cavity receiver 3D heat transfer model.

The fluid properties were evaluated by using the open-access thermodynamic properties database, Coolprop [57]. If an incondensable gas was additionally injected into the liquid water in the tube (for example $\mathrm{CO}_{2}$ ), the gas phases were assumed well mixed with properties calculated based on the molar fractions. Solving the separated flow model requires information on the cross-sectional void fraction, $\varepsilon_{\mathrm{g}}$, which we provided by using an empirical correlation [58]:

$\varepsilon_{\mathrm{g}}=\frac{x_{\mathrm{g}}}{\rho_{\mathrm{g}}}\left[\left(1+0.12\left(1-x_{\mathrm{g}}\right)\right)\left(\frac{x_{\mathrm{g}}}{\rho_{\mathrm{g}}}+\frac{1-x_{\mathrm{g}}}{\rho_{\mathrm{l}}}\right)+\frac{1.18\left(1-x_{\mathrm{g}}\right)\left(g \sigma_{\mathrm{t}}\left(\rho_{1}-\rho_{\mathrm{g}}\right)\right)^{0.25}}{\dot{m}^{\prime \prime} \rho_{l}^{0.5}}\right]^{-1}$,

where $x_{g}$ is the vapor quality in cases when there is no gas injection (i.e. the injection of $\mathrm{CO}_{2}$ for concurrent heating of $\mathrm{H}_{2} \mathrm{O}$ and $\mathrm{CO}_{2}$ for HTE syngas generation) or the gas quality (ratio of the total gas mass to the total fluid mass) in cases when there is gas injection. $\sigma_{t}$ is the temperature-dependent surface tension (obtained from Coolprop) and $\dot{m}^{\prime \prime}$ is the total mass flux. This correlation is the Steiner version of the Rouhani-Axelsson drift flux model, originally proposed for horizontal tubes [59]. It is easy to implement because the void fraction is expressed as an explicit function of the total mass flux. It has been shown that the Steiner version of the Rouhani-Axelsson drift flux model can also be used to estimate the void fraction for inclined and vertical flows with reasonable accuracy (capturing $>80 \%$ date points with $<15 \%$ error) [60]. The Steiner version of the Rouhani-Axelsson drift flux model was consequently an accurate model to flexibly investigate either horizontal, inclined or vertical configurations. Only few other models provide the same flexibility.

\subsubsection{Non-uniform heat transfer coefficients at the inner tube surface}

The heat transfer coefficient between the two-phase mixture and the tube wall were obtained by empirical correlations. The liquid-vapor distribution within the tube has to be known for this and we used suitable heat transfer coefficient correlations for the wetted and nonwetted surfaces. For horizontal tubes, the Thome-El Hajal flow pattern map [61] was used to locally determine the liquid-vapor distribution, i.e. the local flow regimes. This flow pattern map is a modification of the Kattan-Thome-Favrat map [42] which was developed based on Taitel-Dukler map [62]. The Taitel-Dukler map was developed based on water but adiabatic boundary conditions. The Thome-El Hajal flow pattern map was developed based on experimental data for several refrigerants (R-22, R-410A, R-134A, R407C, etc.) for tube diameters between 8 and $14 \mathrm{~mm}$, fluid mass fluxes between 16 and $700 \mathrm{~kg} / \mathrm{m}^{2} / \mathrm{s}$, and heat fluxes between 440 and $57,500 \mathrm{~W} / \mathrm{m}^{2}$. We used the Thome-El Hajal flow pattern map for the various heat fluxes, assuming it is also valid for water. We validated and confirmed the accuracy of this assumption by predicting the water-steam flow regimes in a parabolic trough solar collector for direct steam generation (see Section 3.1.1). The results showed agreement with the experiments with a maximum relative error of $1.2 \%$ for temperature results and $2.2 \%$ for pressure results [63]. We then used the same extrapolation approach for our receiver as the operational conditions were in similar conditions with relatively similar tube geometries and arrangements.

For vertical tubes, the Gungor-Winterton correlation [64] was used to predict the heat transfer before dryout region, and the Groeneveld method [65] in the dryout region. In the 1D two-phase flow model, averaged heat transfer coefficients between the wall and the two-phase fluid were used based on the circumference ratio covered by gas and liquid. The 3D inner tube surface heat transfer coefficient profiles (varying in axial and azimuthal direction) were generated by assigning different heat transfer coefficient values (dry or wet) locally for each azimuthal segment. 3D free stream temperature profiles were obtained by assuming a constant temperature within each axial tube segment and, hence, also a constant temperature in azimuthal direction. The heat transfer coefficient and free stream temperature profiles generated from the 1D tube model were then used as the convective boundary conditions at the inner tube wall in the 3D cavity heat transfer model.

2.2.2.1. Flow pattern maps and heat transfer coefficient for horizontal tubes. The Thome-El Hajal maps predict five flow regimes: stratified flow, stratified wavy flow, intermittent flow, annular flow, and mist flow. The mass flux, $\dot{m}_{\text {strat }}^{\prime \prime}$, of the fluids, the heat flux, $q_{w}$, and the vapor quality, $x_{\mathrm{g}}$, are required for the determination of the flow regime. The transitions between different flow regimes are summarized below.

Stratified flow to stratified wavy flow was defined as:

$\dot{m}_{\text {strat }}^{\prime \prime}=\left[\frac{226.3^{2} A_{\mathrm{g}} A_{1}^{2} \rho_{\mathrm{g}}\left(\rho_{1}-\rho_{\mathrm{g}}\right) v_{l} g}{x_{\mathrm{g}}^{2}\left(1-x_{\mathrm{g}}\right) \pi^{3} d_{\text {tube, in }}^{6}}\right]^{1 / 3}$,

where $A_{\mathrm{g}}$ and $A_{1}$ are the corresponding cross-sectional areas for gas and liquid.

Stratified wavy flow to annular and intermittent flows was defined as: 


$$
\begin{aligned}
\dot{m}_{\text {wavy }}^{\prime \prime}= & \left\{\frac{16 A_{\mathrm{g}}^{3} g \rho_{\mathrm{g}} \rho_{1}}{x_{\mathrm{g}}^{2} \pi^{2} d_{\text {tube,in }}^{5}\left[1-\left(\frac{2 h_{1}}{d_{\text {tube, }, \mathrm{in}}}-1\right)^{2}\right]^{0.5}}\left[\frac{\pi^{2} d_{\text {tube,in }}^{2}}{25 h_{1}^{2}}(1-x)^{-f_{1}(q)}\left(\frac{\mathrm{We}_{\mathrm{e}}}{\mathrm{Fr}_{1}}\right)^{-f_{2}(q)}\right]\right\}^{0.5}+50 \\
& -75 e^{-\frac{\left(x_{\mathrm{g}}^{2}-0.97\right)^{2}}{x_{\mathrm{g}}\left(1-x_{\mathrm{g}}\right)}}
\end{aligned}
$$

where $h_{1}$ is the liquid level, $W e_{1}=\frac{\dot{m}_{1}^{\prime \prime 2} d_{\text {tube,in }}}{\rho_{1} \sigma_{\mathrm{t}}}$ the Weber number for the liquid phase, and $F r_{1}=\frac{\dot{m}_{1}^{\prime \prime 2}}{g \rho_{1}^{2} d \text { tube,in }}$ the Froude number for the liquid phase. $f_{1}(q)$ and $f_{2}(q)$ are two empirical exponents accounting for the effect of the heat flux on the onset of dryout of the annular film,

$f_{1}(q)=646\left(\frac{q_{\mathrm{w}}}{q_{\mathrm{DNB}}}\right)^{2}+64.8 \frac{q_{\mathrm{w}}}{q_{\mathrm{DNB}}}$,

$f_{2}(q)=18.8\left(\frac{q_{\mathrm{w}}}{q_{\mathrm{DNB}}}\right)^{2}+1.023$,

where $q_{\mathrm{DNB}}=0.131 \rho_{\mathrm{g}} h_{\mathrm{lg}}\left[\mathrm{g}\left(\rho_{\mathrm{g}}-\rho_{\mathrm{l}}\right)\right]^{0.25}$ is the heat flux of departure from nucleate boiling. If the mass flux is larger than Eq. (16), we are either in an intermittent or annular flow regime.

Intermittent flow to annular flow was differentiated by:

$x_{\mathrm{g}, \mathrm{IA}}=\left[0.2914\left(\frac{\rho_{\mathrm{g}}}{\rho_{1}}\right)^{-1 / 1.75}\left(\frac{v_{1}}{v_{\mathrm{g}}}\right)^{-1 / 7}\right]^{-1}$.

Annular flow to mist flow was defined as:

$\dot{m}_{\text {mist }}^{\prime \prime}=\left(\frac{7680 A_{g}^{2} g \rho_{\mathrm{g}} \rho_{1} v_{l} F r_{1}}{x_{\mathrm{g}}^{2} \pi^{2} d_{\text {tube, in }}^{3} \xi_{\mathrm{ph}} W e_{1}}\right)^{0.5}$,

where $\xi_{\mathrm{ph}}=\left[1.138+2 \log \left(\frac{\pi d_{\text {tube,in }}^{2}}{1.5 A_{1}}\right)\right]^{-2}$ is the liquid-vapor interfacial friction factor. The transition boundary was adapted by finding the vapor quality, $x_{\text {mist,min }}$, that minimized the mass flux, $\dot{m}_{\text {mist,min }}^{\prime \prime}$, of the mist flow transition curve while enforcing $\dot{m}_{\text {mist }}^{\prime \prime}=\dot{m}_{\text {mist,min }}^{\prime \prime}$ when $x_{\mathrm{g}}>x_{\text {mist,min }}$

Once we identified the flow regime, we were able to estimate how much of the tube area was wetted utilizing the dry angle, $\theta_{\mathrm{dry}}$, defined by the ratio of the dry perimeter to the tube radius. For convenience, the liquid quantity was assumed to be uniformly distributed along the wetting wall by forming a film with a mean thickness, $\delta_{\mathrm{lf}}$. The detailed definition for $\theta_{\mathrm{dry}}$ and $\delta_{\mathrm{lf}}$ for the different flow patterns in horizontal tubes are summarized in Table 1. $x_{\max }$ is the intersection point between $\dot{m}_{\text {wavy }}^{\prime \prime}$ and $\dot{m}_{\text {mist }}^{\prime \prime}$. In stratified wavy flow and for $x_{\mathrm{g}}<x_{\text {max }}$, a linear interpolation between $\dot{m}_{\text {wavy }}^{\prime \prime}$ and $\dot{m}_{\text {mist }}^{\prime \prime}$ was used to predict $\theta_{\text {dry }}$ for a given $\dot{m}$. For $x_{\mathrm{g}} \geq x_{\max }$, the $\theta_{\mathrm{dry}}$ increased linearly from $\theta_{\max }$ to $2 \pi$ with increasing $x_{\mathrm{g}}$. By using an explicit expression of $\varepsilon_{\mathrm{g}}$ as a function of $\dot{m}$ and an approximated geometrical expression for the stratified angle ( $\theta_{\text {strat }}$, the $\theta_{\text {dry }}$ for stratified flow) in terms of $\varepsilon$ [66], the iterative method in the Taitel-Dukler map for the evaluation of $\varepsilon$ and $\theta_{\text {strat }}$ was avoided.

The heat transfer coefficients between the two-phase fluid and tube wall surface for dry, $h_{\mathrm{dry}}$, and wet, $h_{\mathrm{wet}}$, areas were separately calculated using empirical correlations. For $h_{\text {dry }}$, the Dittus-Boelter correlation [67] was used:

$h_{\text {dry }}=0.023\left(\frac{\dot{m}^{\prime \prime} x_{\mathrm{g}} d_{\text {tube, in }}}{\varepsilon_{\mathrm{g}} \mu_{\mathrm{g}}}\right)^{0.8}\left(\frac{c_{\mathrm{pg}} \mu_{\mathrm{g}}}{k_{\mathrm{g}}}\right)^{0.4} \frac{k_{\mathrm{g}}}{d_{\text {tube,in }}}$,

where $c_{\mathrm{pg}}$ is the heat capacity of the gas phase, $k_{\mathrm{g}}$ is the gas phase thermal conductivity, and $\mu_{\mathrm{g}}$ is the dynamic viscosity of the gas phase. $h_{\text {wet }}$ was obtained from an asymptotic expression $\left(h_{\mathrm{wet}}=\left(h_{\mathrm{nb}}^{3}+h_{\mathrm{cb}}^{3}\right)^{1 / 3}\right)$ that combines the nucleate boiling, $h_{\mathrm{nb}}$, and convective boiling, $h_{\mathrm{cb}}$, using an exponent of three, indicating the transition range between the nucleate and convection components. $h_{\mathrm{nb}}$ was determined by an empirical correlation of Coop [64],

$h_{\mathrm{nb}}=55 p_{\mathrm{r}}^{0.12}\left(-\log p_{\mathrm{r}}\right)^{-0.55} M_{\mathrm{H}_{2} \mathrm{O}}^{-0.5} q_{\mathrm{w}}^{0.67}$,

where $p_{\mathrm{r}}$ is the reduced pressure (ratio between fluid pressure and the critical pressure) and $M_{\mathrm{H}_{2} \mathrm{O}}$ is the molar weight of water. $h_{\mathrm{cb}}$ [68] was predicted as,

$h_{\mathrm{cb}}=0.0133\left[\frac{4 \dot{m}^{\prime \prime}\left(1-x_{\mathrm{g}}\right) \delta_{\mathrm{lf}}}{\left(1-\varepsilon_{\mathrm{g}}\right) \mu_{1}}\right]^{0.69}\left(\frac{c_{\mathrm{pl}} \mu_{1}}{k_{1}}\right)^{0.4} \frac{k_{1}}{\delta_{\mathrm{lf}}}$,

where $c_{\mathrm{pl}}$ is the heat capacity of the liquid phase, $k_{1}$ is the liquid phase thermal conductivity, and $\mu_{1}$ is the dynamic viscosity of the liquid phase.

2.2.2.2. Flow pattern maps and heat transfer coefficient for vertical tubes. The flow patterns for flow boiling inside vertical tubes can be classified as bubbly flow, churn flow, annular flow, and mist flow. The dry angle before dryout (mist flow) can be considered as 0 and directly turns into $2 \pi$ at the presence of mist flow. Here, we paid attention to the transition from the annular flow to the mist flow while the flow patterns were not specifically identified. The transition from annular flow to mist flow was defined by the critical vapor quality, $x_{\text {crit }}$, which was predicted by an empirical correlation [69] giving a relation between $x_{\text {crit }}$ and mass flux, pressure, heat flux, and tube diameter:

$x_{\mathrm{g}, \text { crit }}=10.795 q_{\mathrm{w}}^{-0.125} \dot{m}^{\prime \prime-0.333}\left(1000 d_{\text {tube, in }}\right)^{-0.07} e^{1715 p}$.

This correlation is valid for $p<30$ bar. When $x_{\mathrm{g}, \text { crit }}>0.9, x_{\mathrm{g}, \text { crit }}$ was enforced to be 0.9. The Gungor-Winterton correlation [70] was used to predict the heat transfer coefficient, $h_{\text {wet }}$, before dryout, being the sum of convective heat transfer of the liquid phase, $h_{\mathrm{cb}}$, using the Dittus-Boelter correlation and nucleate pool boiling, $h_{\mathrm{nb}}$, from the Coop correlation [64]:

$h_{\mathrm{wet}}=E h_{\mathrm{cb}}+S h_{\mathrm{nb}}$,

where $E$ is the two-phase convection multiplier which is a function of the Martinelli parameter, heat flux, and $S$, which is the boiling suppression factor based on $E$ and Reynold number of the liquid phase. The heat transfer coefficient of the dryout region, $h_{\mathrm{dry}}$, was predicted by the Groeneveld method [65].

2.2.2.3. Heat transfer coefficient in titled and helical tubes. Since the reported flow pattern maps for the flow boiling phenomena in titled and helical tubes are very limited, we used approximations and interpolations based on the horizontal and vertical flow maps and correlations to predict the heat transfer coefficient. The horizontal flow was considered when the control volume has an inclination angle in the range of $0-30^{\circ}$. The flow was treated as vertical flow when the inclination angle was between $60^{\circ}$ and $90^{\circ}$. A linear interpolation of heat transfer coefficient between horizontal and vertical flows was implemented for the control volumes with inclination angle between $30^{\circ}$ and $60^{\circ}$. In the curved helical tube, slower moving fluid elements move toward the inner wall of the curved tube as a result of the momentum balance between the momentum change caused by the

Table 1

\begin{tabular}{|c|c|c|c|}
\hline Flow pattern & Sub-regions & $\theta_{\mathrm{dry}}$ & $\delta_{\text {lf }}$ \\
\hline Stratified & None & $\theta_{\text {strat }}$ & $\pi d_{\text {tube, in }}(1-\varepsilon)$ \\
\hline \multirow[t]{2}{*}{ Stratified wavy } & $x_{\mathrm{g}}<x_{\max }$ & $\theta_{\text {strat }} \frac{\dot{m}_{\text {Wavy }}^{\prime \prime}\left(x_{\mathrm{g}}\right)-\dot{m}^{\prime \prime}}{\dot{m}_{\text {wavy }}^{\prime \prime}\left(x_{\mathrm{g}}\right)-\dot{m}_{\text {strat }}^{\prime \prime}\left(x_{\mathrm{g}}\right)}$ & $\begin{array}{l}\overline{2\left(2 \pi-\theta_{\text {dry }}\right)} \\
\text { (if } \delta_{\text {lf }}>0.5 d_{\text {tube,in, }}\end{array}$ \\
\hline & $x_{\mathrm{g}}>x_{\max }$ & $\left(2 \pi-\theta_{\max }\right) \frac{x_{\mathrm{g}}-x_{\max }}{1-x_{\max }}+\theta_{\max }$ & $\left.\delta_{\text {lf }}=0.5 d_{\text {tube, in }}\right)$ \\
\hline $\begin{array}{l}\text { Annular and } \\
\text { Intermitte- } \\
\text { nt }\end{array}$ & None & 0 & \\
\hline Mist & None & $2 \pi$ & 0 \\
\hline
\end{tabular}

Summary of $\theta_{\mathrm{dry}}$ and $\delta_{\mathrm{lf}}$ for different flow patterns in horizontal tube [61]. 
centrifugal force and the momentum change induced by the pressure gradient. This drift leads to the occurrence of secondary flows in the flowing fluid [72]. Secondary flows, in turn, lead to an augmentation in heat transfer with the magnitude of this increase depending on the coil curvature $\left(d_{\text {tube, in }}\right.$ and $\left.r_{\text {turn }}\right)$. Here, the secondary flow was not considered in the fluid flow model. However, we considered the enhancement due to secondary flow in helical tube by correcting the heat transfer coefficient based on the helical turning radius and the tube radius. Two heat transfer enhancement factors $\left(1+1.77 d_{\text {tube,in }} / r_{\text {turn }}\right.$ for gas phase and $1+10.3\left(d_{\text {tube, in }} / r_{\text {turn }}\right)^{3}$ for liquid phase) were considered for helical tube receivers [71], accounting for the heat transfer enhancement induced by secondary flows.

\subsubsection{Heat transfer in single phase flow region}

The local heat transfer coefficients for the liquid single phase flow region was predicted using an empirical correlation proposed by Liu et al. [36] by considering both forced convective contribution and subcooled boiling (based on temperature differences between tube wall and bulk fluid as well as tube wall and saturation temperature). The heat transfer coefficient for gas single phase flow region was simply predicted by the Dittus-Boelter correlation (Eq. (20)).

\subsection{Model coupling}

The 3D receiver cavity heat transfer model and the 1D tube fluid flow model were solved iteratively using a simulation flow as shown in Fig. 2. The calculation started with the 1D tube model using the input parameters (i.e. $\dot{m}, p, T_{\text {inlet }}$ ) and an initial guess for the heat flux, $q_{\mathrm{w}, \text { ini }}$. A $3 \mathrm{D}$ heat transfer coefficient profile and a 3D fluid temperature profile along the tube inner wall surface were generated based on the model described in Section 2.2. These two profiles were then applied to the 3D receiver cavity model as a convective boundary condition at the inner tube wall. The results of the 3D receiver cavity model provided a 1D heat flux profile to the 1D tube model by azimuthal-averaging the heat flux calculated from the 3D cavity model for each axial tube segment and applying it to the inner tube surfaces. The overall convergence was controlled by the relative error in the temperature $\left(T_{j}\right.$, temperature for each node $j$ ) between two iterations (i.e. between iteration $i$ and $i-1$ ) with a tolerance of $10^{-3}$ to ensure an overall energy imbalance smaller than $0.5 \%$.

\subsection{Numerical solution}

The numerical discretization of the 1D tube model for the two-phase flow inside the receiver tubes relied on the control volume formulation, solved with an implicit step-by-step method in the flow direction $[39,40]$. The convergence criterion in each control volume for continuity, momentum, and energy equations were set to $10^{-8}$. The 3D receiver cavity heat transfer model was implement with a commercial solver, ANSYS FLUENT version 17.2 [73]. The surface-to-surface radiation model was solved with a residual of $10^{-8}$. The energy equation was discretized by a second order upwind scheme with a residual value of $10^{-7}$. The global convergence criterion of the coupled $1 \mathrm{D}$ and $3 \mathrm{D}$ model was the fluid temperature between two successive global iterations, where the convergence criterion was set to $10^{-3}$. All convergences criterion values were chosen to ensure an energy imbalance for all studied cases smaller than $0.5 \%$.

A mesh independent study showed that a reasonable meshing scheme for the tubes consisted of 1000 uniform elements $(\sim 330$ elements per meter) in flow direction (kept the same for the 1D fluid flow model) and 30 uniform elements in azimuthal direction (30 elements over $360^{\circ}$ ), resulting in a total mesh element number of about 1 million cells for the 3D heat transfer model. Further increase in the mesh element number resulted in less than $\sim 1 \mathrm{~K}$ difference for the predicted outlet fluid temperature. A workstation with 24 GB RAM and 10 cores was utilized to compute the coupled modele.

For the receiver 1 at the reference conditions, it took $\sim 4 \mathrm{~h}$ to have the final convergence (16 iterations between the receiver cavity heat transfer model and the tube fluid flow model). For receiver 2 at the reference conditions, it took $\sim 4.5 \mathrm{~h}$ for a complete convergence (17 iterations between cavity model and the tube model). The computational time for cases with varying operational and geometrical conditions took a similar amount of time (for each calculation).

\section{Results and discussion}

\subsection{Model validation}

\subsubsection{Comparison to parabolic trough concentrator}

Due to lack of reported experimental data for direct steam generation receiver demonstrations in solar point-focusing concentrating facilities (towers and dishes), we utilized experimental data for direct steam generation in a parabolic trough solar collector for the validation of our two-phase flow model and for checking if our flow pattern map extrapolation approach (see Section 2.2.2) was accurate. The geometrical data and operational conditions were set to be identical to what has been reported by Lobon et al. [74]. The validation with their example case 1 is shown in Fig. 3.

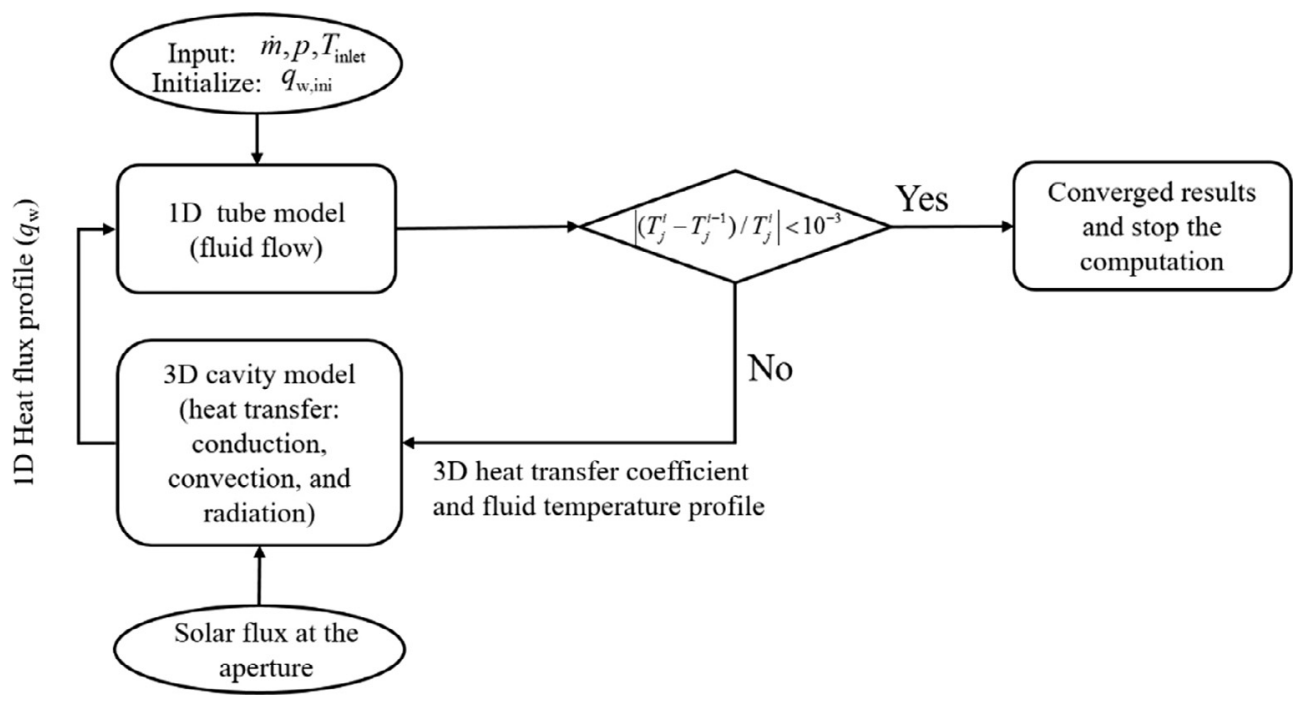

Fig. 2. Schematic of the coupling between the 1D tube model and the 3Dreceiver cavity heat transfer model. 
The detailed parameters used for the model validation are summarized in Table S1. Our model accurately predicted the evolution of the temperature, pressure, heat and transfer coefficient (averaged value over azimuthal direction for each axial segment) along the flow direction. A slight over estimation in the temperature and underestimation in the pressure in the superheated region were observed (Fig. 3a).

This agreement led us to conclude that the flow pattern maps can indeed be used for diabatic water-steam flows. We associate the discrepancy between experimental data and the predicted value with inaccurate heat loss data from reference [74] in the superheating region. Our model was then used to predict the flow pattern evolution along the flow direction, information inaccessible in an actual experiment. 82.9\% of the tube length was exposed to two-phase flow. As shown in Fig. 3b, the two-phase flow started with stratified wavy flow $(26.8 \%$ of twophase flow region or tube length) and switched to intermittent $(6.2 \%$ of two-phase flow region or tube length) and to annular flow (64.7\% of two-phase flow region or tube length) when the vapor quality reached 0.27 . The flow started to dry out at a critical vapor quality of 0.98 for the last $2 \%$ of the tube length.

\subsubsection{Comparison to DLR receiver experiment utilizing a high-flux solar simulator}

The temperature measurements for a helical tube receiver from the experimental campaigns at the Deutsches Zentrum für Luft- und Raumfahrt (DLR) in the high-flux solar simulator in Cologne were used for the helical tube model validation. A helical tube with height, $H_{\text {helical }}$, of $310 \mathrm{~mm}$, tube outer diameter, $d_{\text {tube,out }}$, of $10 \mathrm{~mm}$, tube thickness of $1 \mathrm{~mm}$, and turning radius, $r_{\text {turn }}$, of $75 \mathrm{~mm}$ was used. The major components of the experimental setup at DLR are shown in Fig. 4a. The inlet water mass flow was controlled by a mass flow controller with an accuracy of $\pm 0.4 \%$. The pump was connected to an independent closedloop water system to guarantee a constant pressure level (6 bar) at the flow inlet. A steam separator was used to separate liquid water and vapor in the outlet fluids. The vapor flow was then condensed in a water-cooled condenser. Three pressure transducers were used to measure the inlet (one transducer) and outlet (two transducers: one for the pressure before the steam generator, and one for the vapor pressure after the steam generator) fluid pressures with an accuracy of $\pm 0.2 \%$. K-type thermocouples were welded to the helical tube surface for the measurement of the tube surface temperatures. K-type thermocouples inserted into T-connectors were used to measure the inlet and outlet fluid temperatures. The thermocouples were calibrated by a Klasmeier thermocouple calibrator and showed an accuracy of $\pm 1 \mathrm{~K}$. Fig. S3a shows a side view of the helical tube indicating the positions of the thermocouples used for the temperature measurements. Their exact positions are listed in Table S2. A conically shaped diffuser was added in the receiver with a bottom diameter of $100 \mathrm{~mm}$ and a height of $260 \mathrm{~mm}$ with the purpose of achieving a more uniform temperature distribution on the helical tube. Measured temperatures and inlet pressures over time are shown in Fig. S3b with an inflow of liquid water of $3 \mathrm{~kg} / \mathrm{h}$ at an inlet temperature of $416 \mathrm{~K}$, inlet pressure of $4.4 \mathrm{bar}$, and $1.51 \mathrm{~kW}$ solar power input (peak irradiation at aperture $750 \mathrm{~kW} / \mathrm{m}^{2}$, predicted local peak heat flux on tube surface is $47.6 \mathrm{~kW} / \mathrm{m}^{2}$, which is within the upper limit for the flow pattern map).

Fig. 4 compares our calculated temperatures with the experimental data. In general, the model accurately predicted the tube surface temperatures. The deviation between the simulated and experimental data in the front (positions 2-6) are associated with a non-diffuse irradiation in the experiment and the detachment of one thermocouple from the surface (position 13). The measured fluid outlet temperature was $417 \mathrm{~K}$ with vapor quality of 0.57 . The model accurately predicted the outlet fluid conditions with relative deviations of $0.65 \%$ and $7 \%$ for the temperature (predicted value: $420 \mathrm{~K}$ ) and vapor quality (predicted value: 0.61 , respectively.

\subsection{Reference cases results}

One reference case for two types of receivers was defined (see table 2). The number of tubes in receiver 2 was determined by approximating closely the same total tube length as the helical tube in receiver 1 (3.02 $\mathrm{m}$ for receiver 1 and $3.04 \mathrm{~m}$ for receiver 2 ). The fluid inlet was assumed to be at the rear of the cavity (see Fig. 1) for receiver 1 . The tubes in receiver 2 were connected in series with the outlet of one tube connected to the inlet of the successive tube. The fluid temperature profiles along the tube and the pressure for the two receivers under reference conditions are shown in Fig. 5a and the detailed energy balance are presented in Fig. 5b. The local heat flux along the tube length is shown in Fig. S5 indicating the maximum heat flux may exceed $\sim 90 \mathrm{~kW} / \mathrm{m}^{2}$, a flux magnitude beyond the validated heat flux for the flow pattern map. The extrapolation of the map to these heat fluxes was not validated. Under reference conditions with $1.5 \mathrm{~kW}$ incident solar power at the aperture, the receiver $1(80.3 \%)$ showed better solar-tothermal efficiency, $\eta_{\mathrm{STT}}$, than receiver 2 (78.6\%). The $T_{\text {fluid,out }}$ for receiver 1 was $1068 \mathrm{~K}$, and $1029 \mathrm{~K}$ for receiver 2 . The pressure drop for receiver 2 was higher compared to receiver 1 due to a longer and higher velocity superheating region. Receiver 1 showed higher $\dot{Q}_{\text {rerad }}(8.4 \%)$ than receiver $2(7.9 \%)$ due to higher surface temperatures close to the aperture (see Fig. 5c and d). Receiver 2 showed larger $\dot{Q}_{\text {conv }}$ and $\dot{Q}_{\text {cond }}$ compared to receiver 1 (see Fig. $5 \mathrm{~b}$ ) due to a larger averaged tube surface temperature $(741 \mathrm{~K}$ for receiver $2,609 \mathrm{~K}$ for receiver 1$)$.

A larger input power scenario of $\dot{Q}_{\text {solar }}=10 \mathrm{~kW}$ was created for which an increased flow rate of $0.0021 \mathrm{~kg} / \mathrm{s}$ was used. This flow rate was determined by multiplying the $0.0003 \mathrm{~kg} / \mathrm{s}$ (reference value at $\dot{Q}_{\text {solar }}=1.5 \mathrm{~kW}$ ) with the solar power ratio and artificially increasing it by $5 \%$ to ensure that the outlet temperature was smaller than $\sim 1200 \mathrm{~K}$ (an upper temperature considered safe for stainless steel tubes). $\eta_{\mathrm{STT}}$ of both receivers increased $(91.5 \%$ for receiver 1 and $90.5 \%$ for receiver
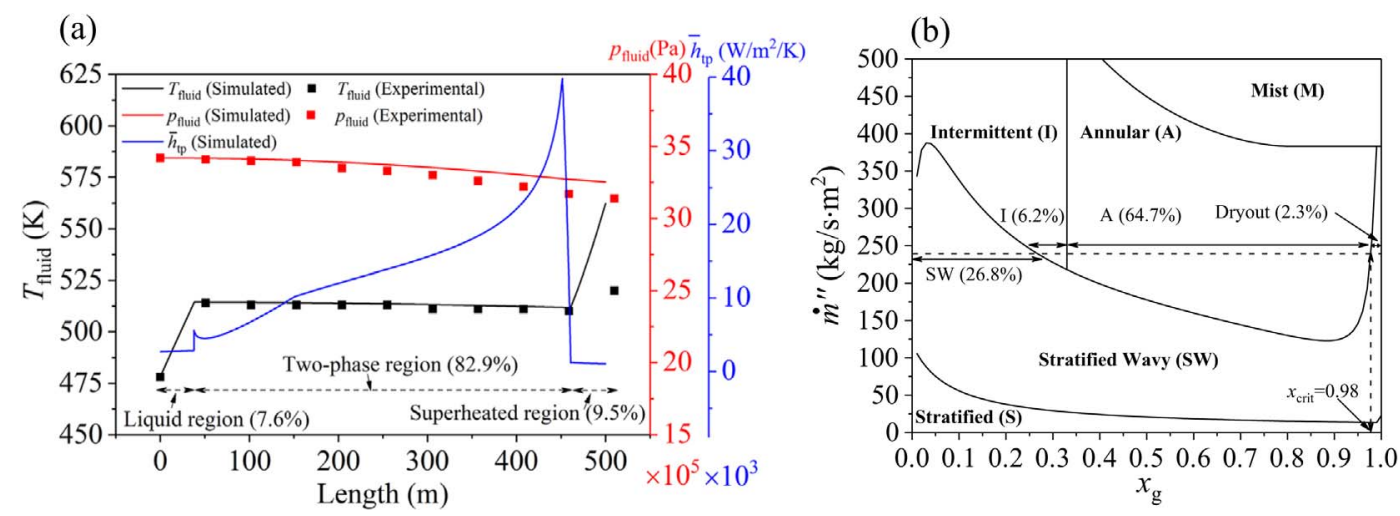

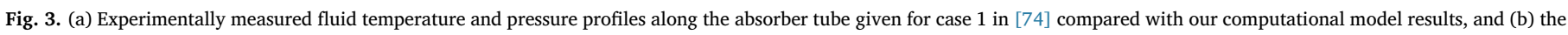
calculated flow pattern evolution for case 1 at the averaged flux of $q_{\mathrm{w}}=\sim 12.3 \mathrm{~kW} / \mathrm{m}^{2}$ (calculated peak flux was up to $25.7 \mathrm{~kW} / \mathrm{m}^{2}$ ). 

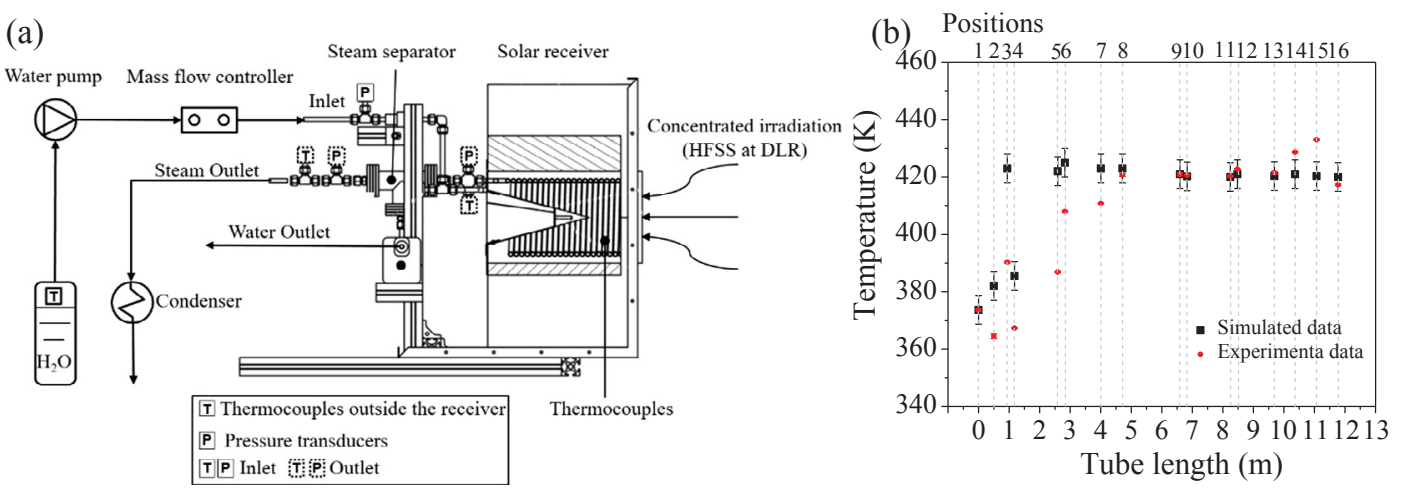

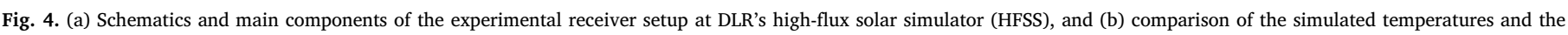

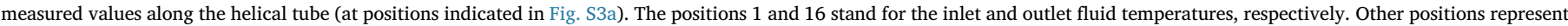

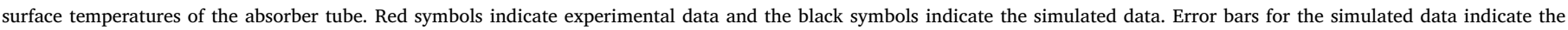
position uncertainties of thermocouples $( \pm 1 \mathrm{~mm}$ ) and errors bars for experiment data result from the standard deviation over the steady state testing time of $\sim 2 \mathrm{~h}$.

Table 2

Reference case parameters used for receiver 1 and receiver 2.

\begin{tabular}{ll}
\hline Parameters & Value \\
\hline Cavity inner diameter, $d_{\text {cav }}$ & $0.09 \mathrm{~m}$ \\
Cavity length, $L_{\text {cav }}$ & $0.09 \mathrm{~m}$ \\
Aperture outer diameter, $d_{\text {ap }}$ & $0.05 \mathrm{~m}$ \\
Aperture inner diameter, $d_{\text {ap,in }}$ & $0.07 \mathrm{~m}$ \\
Insulation diameter, $d_{\text {insu }}$ & $0.18 \mathrm{~m}$ \\
Insulation length, $L_{\text {insu }}$ & $0.14 \mathrm{~m}$ \\
Height of helical tube (receiver 1), $H_{\text {helical }}$ & $0.08 \mathrm{~m}$ \\
Helical turning radius (receiver 1 ), $r_{\text {turn }}$ & $0.04 \mathrm{~m}$ \\
Length of helical tube (receiver 1 ), $L_{\text {tube, } 1}$ & $3.02 \mathrm{~m}$ \\
Length of single tube (receiver 2$), L_{\text {tube, }}$ & $0.08 \mathrm{~m}$ \\
Number of tubes (receiver 1 ), $N_{\text {tube, } 1}$ & 1 \\
Number of tubes (receiver 2), $N_{\text {tube, }, 2}$ & 38 \\
Tube outer diameter, $d_{\text {tube,out }}$ & $0.006 \mathrm{~m}$ \\
Tube inner diameter, $d_{\text {tube,in }}$ & $0.005 \mathrm{~m}$ \\
Surface emissivity of insulation, $\varepsilon_{\text {insu }}$ & 0.5 \\
Surface emissivity of tube, $\varepsilon_{\text {tube }}$ & 0.9 \\
Fluid inlet temperature, $T_{\text {fluid,in }}$ & $303.15 \mathrm{~K}$ \\
Fluid inlet pressure, $p_{\text {fluid,in }}$ & $5 \mathrm{bar}$ \\
Inlet flow rate, $\dot{m}_{\text {tube,in }}$ & $3 \cdot 10^{-4} \mathrm{~kg} / \mathrm{s}$ \\
Incident solar power at aperture, $Q_{\text {solar }}$ & $1.5 \mathrm{~kW} \mathrm{and} 10 \mathrm{~kW}$ \\
Standard deviation of flux distribution, $\delta_{x}$ & $0.026 \mathrm{~m}$ \\
& \\
&
\end{tabular}

2) for the larger input power scenario. The increase of $\eta_{\text {STT }}$ was attributed to the increasing average concentration ratio (increased from 764 to 5093 for receivers 1 and 2) and increasing surface-averaged heat transfer coefficients (increased from $3022 \mathrm{~W} / \mathrm{m}^{2} / \mathrm{K}$ to $8567 \mathrm{~W} / \mathrm{m}^{2} / \mathrm{K}$ for receiver 1 , and from $882 \mathrm{~W} / \mathrm{m}^{2} / \mathrm{K}$ to $4825 \mathrm{~W} / \mathrm{m}^{2} / \mathrm{K}$ for receiver 2 ) when $\dot{Q}_{\text {solar }}$ increased from $1.5 \mathrm{~kW}$ to $10 \mathrm{~kW}$. The $\dot{Q}_{\text {rerad }}$ dominated the heat losses at $Q_{\text {solar }}=10 \mathrm{~kW}$ due to increased average tube surface temperature ( $666 \mathrm{~K}$ for receiver 1 and $780 \mathrm{~K}$ receiver 2 ). However, the efficiency of receiver 2 was still inferior to the one of receiver 1 due to much higher $\dot{Q}_{\text {cond }}$ which counteracted the benefit from lower $\dot{Q}_{\text {rerad }}$ (Fig. 5b). This efficiency difference was reduced at larger $\dot{Q}_{\text {solar }}$ due to increased difference in $\dot{Q}_{\text {rerad }}$. For instance, the absolute efficiency difference between receiver 1 and receiver 2 was $1.7 \%$ at $\dot{Q}_{\text {solar }}=1.5 \mathrm{~kW}$ and $1 \%$ at $\dot{Q}_{\text {solar }}=10 \mathrm{~kW}$.

Our model can also be used for the concurrent heating of a water and $\mathrm{CO}_{2}$ mixture, a scenario interesting for studying syngas production in STEP and SHTE applications. The corresponding reference case results are shown in Fig. S4 with the $\mathrm{CO}_{2}$ molar fraction varying from 0 to 1 while other parameters were kept at the reference condition. In general, the $\eta_{\text {STT }}$ decreases with an increasing inlet molar fraction of $\mathrm{CO}_{2}$ resulting from higher fluid outlet temperatures for the same solar input (see Fig. S4), which led to higher averaged tube surface temperatures and, correspondingly, higher heat losses. The increase in the fluid outlet temperature with increasing inlet molar fraction of $\mathrm{CO}_{2}$ resulted from the reduced (latent) heat demand with the decreasing water flow at the inlet. The addition of $\mathrm{CO}_{2}$ to the water led to two competing effects in terms of heat transfer: (i) its increase in the subcooled region due to the higher fluid velocity, and (ii) its decrease due to the reduced length of the two-phase flow region. At a small inlet molar fraction of $\mathrm{CO}_{2}(10-20 \%)$, the decrease in $\eta_{\mathrm{STT}}$ due to reduced heating demand is minor while the heat transfer coefficient enhancement in the subcooled region is significant leading to a more efficiency mixture heating than individual heating of water and $\mathrm{CO}_{2}$.

\subsection{Flow rates}

The outlet fluid temperature $T_{\text {fluid,out }}, \eta_{\mathrm{STT}}$, and outlet vapor quality, $x_{\text {out }}$, are shown as a function of the fluid flow rate, $\dot{m}_{\mathrm{H}_{2} \mathrm{O} \text {,in }}$, in Fig. $6 \mathrm{a}$. As $\dot{m}_{\mathrm{H}_{2} \mathrm{O} \text {,in }}$ increased from $0.3 \mathrm{~g} / \mathrm{s}$ to $1 \mathrm{~g} / \mathrm{s}$, for receiver $1, T_{\text {fluid,out }}$ decreased from $1068 \mathrm{~K}$ to $425 \mathrm{~K}, \eta_{\mathrm{STT}}$ decreases from $80.4 \%$ to $89.3 \%$, and $x_{\text {out }}$ decreased from 1 (superheated steam) to 0.39 . The significant increase in $\eta_{\text {STT }}$ with increasing $\dot{m}_{\mathrm{H}_{2} \mathrm{O} \text {,in }}$ can be attributed to significant decrease of $\dot{Q}_{\text {rerad }}\left(\dot{Q}_{\text {rerad }}\right.$ was $161.1 \mathrm{~W}$ at $0.3 \mathrm{~g} / \mathrm{s}$ and $57.2 \mathrm{~W}$ at $1 \mathrm{~g} / \mathrm{s}$, see Fig. $6 \mathrm{~b}$ ). Receiver 2 showed similar behavior as receiver 1 in a flow rate range of $0.3 \mathrm{~g} / \mathrm{s}$ to $1 \mathrm{~g} / \mathrm{s}$. The increase in $\eta_{\mathrm{STT}}$ reduced when $\dot{m}_{\mathrm{H}_{2} \mathrm{O} \text {,in }}$ was larger than $0.45 \mathrm{~g} / \mathrm{s}$ for receiver 1 and $0.41 \mathrm{~g} / \mathrm{s}$ for receiver 2 (see Fig. 6a), respectively, both due to the reduced benefit from the decreasing reradiation losses with increasing flow rate. Note that receiver 1 and receiver 2 were not able to produce superheated steam when the flow rate was above $0.55 \mathrm{~g} / \mathrm{s}$ and $0.5 \mathrm{~g} / \mathrm{s}$, respectively, both at reference conditions.

As $\dot{m}_{\mathrm{H}_{2} \mathrm{O}, \text { in }}$ further increased from $1 \mathrm{~g} / \mathrm{s}$ to $1.6 \mathrm{~g} / \mathrm{s}, \eta_{\mathrm{STT}}$ of receiver 1 continued to increase from 89.3 to $89.5 \%$ while for receiver 2 it decreased from $87.0 \%$ to $86.3 \%$. This further increase of $\eta_{\text {STT }}$ for receiver 1 with increasing flow rate was mostly due to a decrease of $\dot{Q}_{\text {conv }}$ (from $33.6 \mathrm{~W}$ to $30.7 \mathrm{~W}$ ) and $\dot{Q}_{\text {cond }}$ (from $74.1 \mathrm{~W}$ to $73.1 \mathrm{~W}$ ). As for receiver 2, the decrease in $\eta_{\text {STT }}$ resulted from the increase in all three heat loss terms (see Fig. 6c), attributed to the reduction in heat transfer coefficient resulting from reduced tubular length in the two-phase flow region $\left(x_{\text {out }}=0.38\right.$ at $1 \mathrm{~g} / \mathrm{s}$ and $x_{\text {out }}=0.14$ at $1.6 \mathrm{~g} / \mathrm{s}$ ).

The receiver's thermal performance with varying flow rates offers useful information for designing direct steam generation solar receivers with a desired outlet temperature. For example, for a desired fluid outlet temperature of $\sim 950 \mathrm{~K}$, receiver 2 is the more reasonable choice as both receiver have identical $\eta_{\mathrm{STT}}$ while receiver 2 exhibits less stringent temperature gradients (see Fig. $5 \mathrm{c}$ and d).

\subsection{Pressure}

We varied the fluid inlet pressure from 1 to 25 bar. The corresponding fluid outlet temperature and solar-to-thermal efficiency are 
(a)

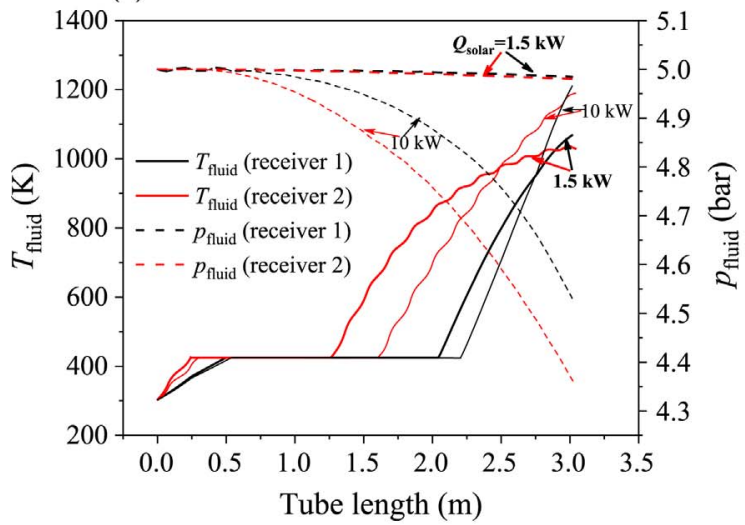

(c) $T(\mathrm{~K})$

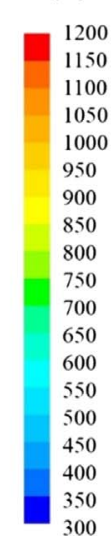

(b)

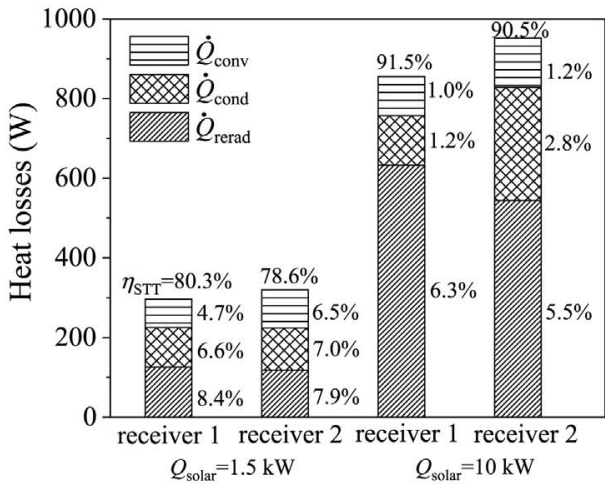

(d)

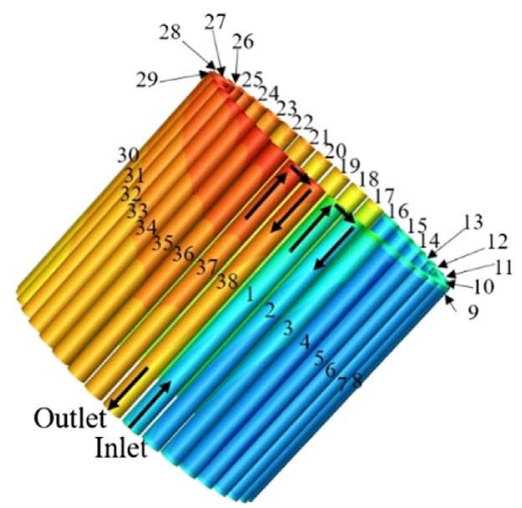

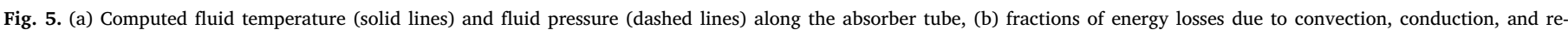

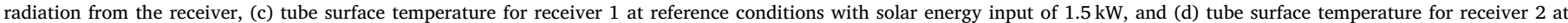

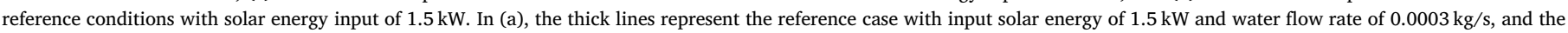

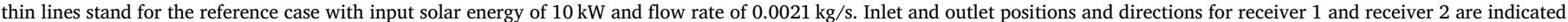
with arrows. Tube connection sequence for receiver 2 is indicated by tube numbers (from 1 to 38 ).

shown in Fig. 7a, and the heat loss compositions in Fig. 7b. When the fluid inlet pressure increased from 1 to $10 \mathrm{bar}$, the solar-to-thermal efficiency slightly decreased for receiver 1 (from $80.3 \%$ to $80.1 \%$ ) while it stayed constant for receiver $2(78.6 \%)$. The decrease in efficiency for receiver 1 was attributed to the increasing conductive and convective heat losses (see Fig. 7b). It is interesting to note that the outlet temperature increased from $1065 \mathrm{~K}$ to $1070 \mathrm{~K}$ although the efficiency decreased under reference conditions. This resulted from the decreased enthalpy difference with increasing pressure required to achieve the same temperature. When pressure was further increased from 10 bar to $15 \mathrm{bar}$, receiver 1 showed a decrease in the solar-to-thermal efficiency (80.4-79.5\%) due to the higher saturation temperatures at higher pressure and the corresponding increase in the average surface temperature $(620 \mathrm{~K}-640 \mathrm{~K})$, which dominated and increased the heat losses (see Fig. 7b). For pressures above 15 bars, the solar-to-thermal efficiency was constant for receiver 1 as the benefit from the increased (a)

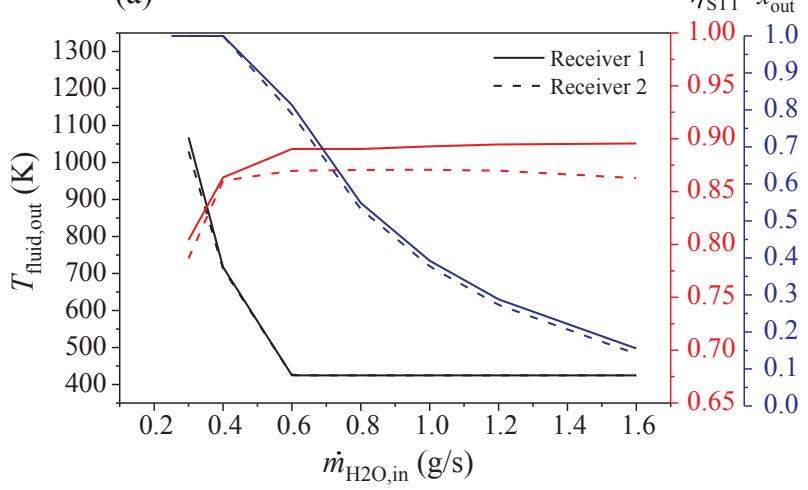

(b)

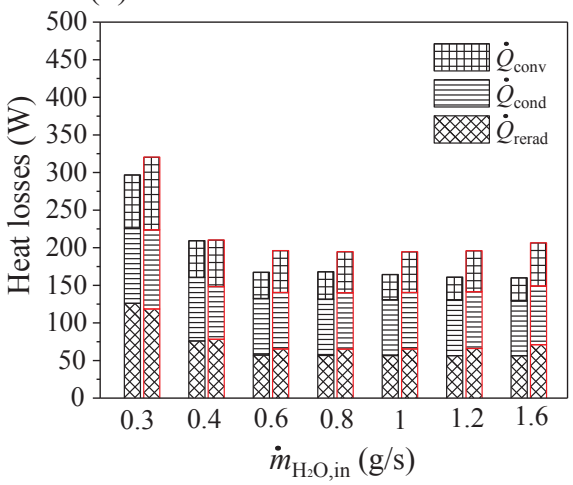

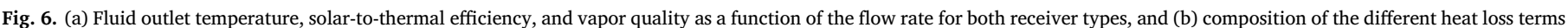

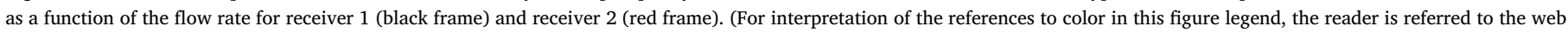
version of this article.) 
(a)

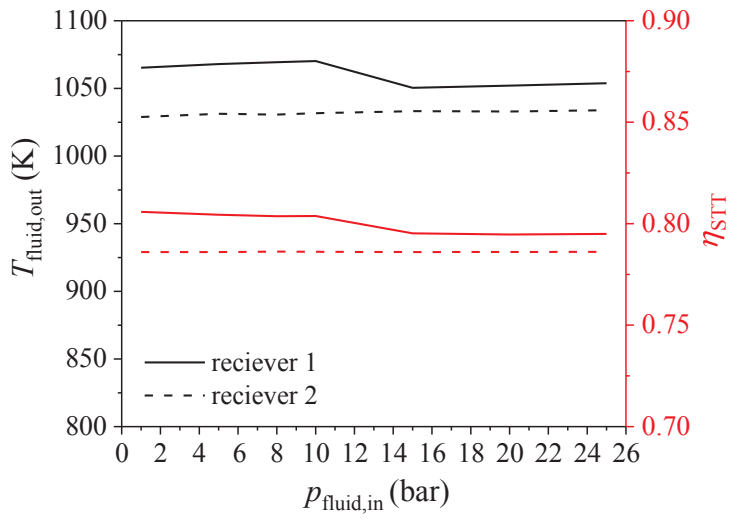

(b)

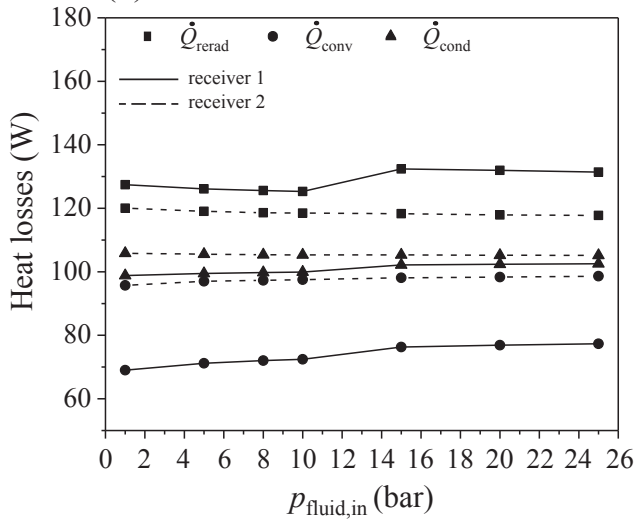

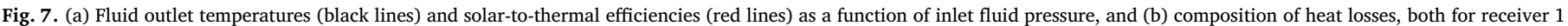
(solid lines) and receiver 2 (dotted lines). (For interpretation of the references to color in this figure legend, the reader is referred to the web version of this article.)

enthalpy difference counteracted the disadvantage in heat transfer losses. The performance of receiver 2 was not sensitive to changes in pressure as the temperature was more uniformly distributed in the receiver.

\subsection{Surface emissivity}

The fluid outlet temperature and solar-to-thermal efficiency as a function of the tube surface emissivity are shown in Fig. 8a. The emissivity of the receiver cavity inner surfaces was kept at our reference value of 0.5. In general, the solar-to-thermal efficiency and the fluid outlet temperature increased with increasing surface emissivity (see Fig. 8a), resulting from sharply reduced re-radiation losses (see Fig. 8b). Receiver 2 showed larger solar-to-thermal efficiencies than receiver 1 , in the case when $\varepsilon_{\text {tube }}$ was smaller than 0.58 . This was due lower reradiation losses for receiver 2 compared to receiver 1 (i.e. $\dot{Q}_{\text {rerad }}=505 \mathrm{~W}$ for receiver 1 and $437 \mathrm{~W}$ for receiver 2 at $\varepsilon_{\text {tube }}=0.1$ ), which compensated the higher conductive and convective losses for receiver 2 . At $\varepsilon_{\text {tube }}=0.58$, both receiver types show identical performance. Further increase of $\varepsilon_{\text {tube }}$ (above 0.58 ) led to higher performance for receiver 1 , caused by a reduced difference in the re-radiation losses due to better absorption behavior.

These results provide guidance for the best surface emissivity and correspondingly guide the choice of coating materials (emissivities above 0.8 increase the efficiency only minimal, by less than $0.5 \%$ ). In addition, the receiver selection (helical tube or multi-tube) can be adapted depending on the choice or availability of the emissivity of the solar absorber surfaces.

(a)

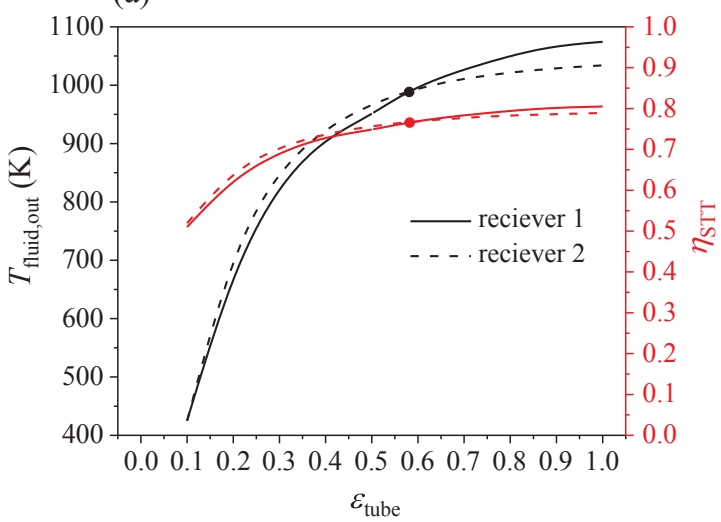

\subsection{Effect of fluid inlet position}

The effect of the fluid inlet position on the performance of receiver 1 is shown in Fig. 9. The fluid inlet position was assumed to be at the rear in the reference case. This inlet configuration showed better $\eta_{\mathrm{STT}}$ at $\dot{Q}_{\text {solar }}=1.5 \mathrm{~kW}\left(\eta_{\text {STT }}=80.3 \%\right)$ than the case with the inlet position at the front (co-located with the solar irradiation position) of the receiver $\left(\eta_{\mathrm{STT}}=78.6 \%\right)$. This advantage in $\eta_{\mathrm{STT}}$ led to higher outlet fluid temperature $(1068 \mathrm{~K}$ at rear vs. $1030 \mathrm{~K}$ front). The inlet position at the front led to longer sub-cooled and two-phase flow regions than the case with the inlet position at the rear, which led to a lower average tube surface temperature $(610 \mathrm{~K}$ at front vs. $816 \mathrm{~K}$ rear). This in turn resulted in lower $\dot{Q}_{\text {conv }}$ and $\dot{Q}_{\text {cond }}$ with a front inlet. $\dot{Q}_{\text {conv }}$ and $\dot{Q}_{\text {cond }}$ dominated the heat losses at $\dot{Q}_{\text {solar }}=1.5 \mathrm{~kW}$ (see Fig. 9) which favored the rear inlet case. However, the front inlet case showed lower re-radiation heat losses because of the better heat transfer near the aperture which, in turn, led to lower tube surface temperatures near the aperture. Compared to the front inlet case, the decrease of $\dot{Q}_{\text {conv }}$ and $\dot{Q}_{\text {cond }}$ with the inlet position at the rear counteracted the increase of $\dot{Q}_{\text {rerad }}$, which caused a decrease in $\eta_{\mathrm{STT}}$. When the $\dot{Q}_{\text {solar }}$ increased from $1.5 \mathrm{~kW}$ to $10 \mathrm{~kW}$, the front inlet position showed larger $\eta_{\mathrm{STT}}(92.3 \%)$ than the rear inlet position (91.4\%). This was due to the domination of $\dot{Q}_{\text {rerad }}$ (see Fig. 9b) at higher $\dot{Q}_{\text {solar }}$ and the advantage of having smaller $\dot{Q}_{\text {rerad }}$ $(498 \mathrm{~W})$ for the front inlet case $(633 \mathrm{~W})$ than the rear inlet case, which overshadowed the larger convective and conductive heat losses for the front inlet case $\left(\dot{Q}_{\text {conv }}+\dot{Q}_{\text {cond }}=223 \mathrm{~W}\right.$ for rear inlet case, and $269 \mathrm{~W}$ for front inlet case).

Consequently, a smart choice of the flow inlet position can boost the

(b)

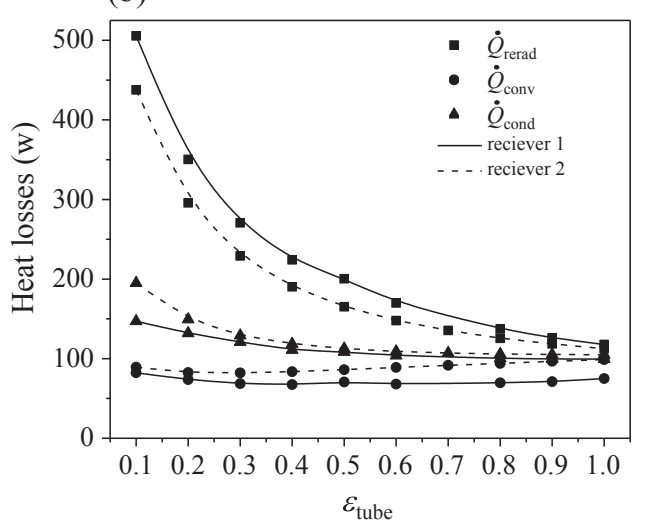

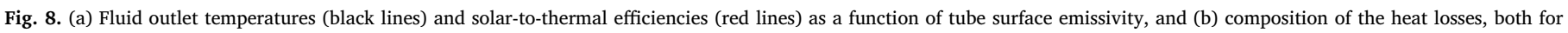
receiver 1 (solid lines) and receiver 2 (dotted lines). (For interpretation of the references to color in this figure legend, the reader is referred to the web version of this article.) 
(a)

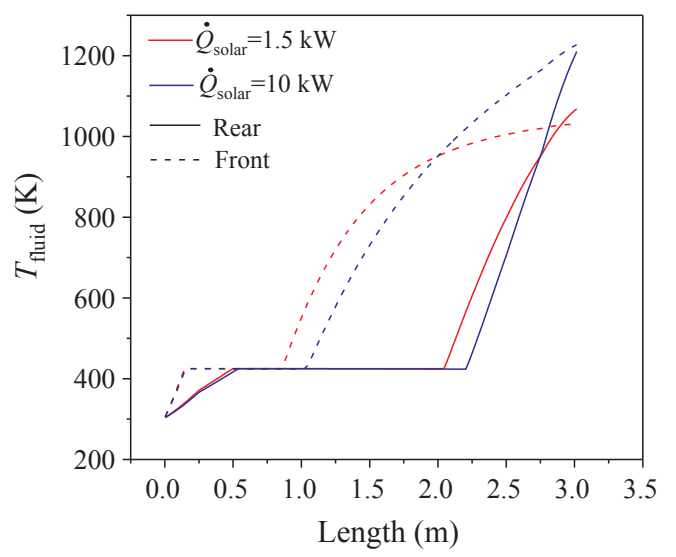

(c)

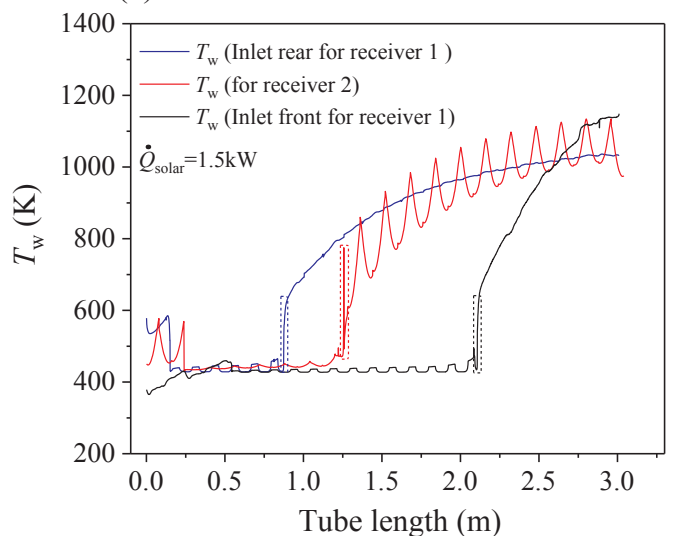

(b)

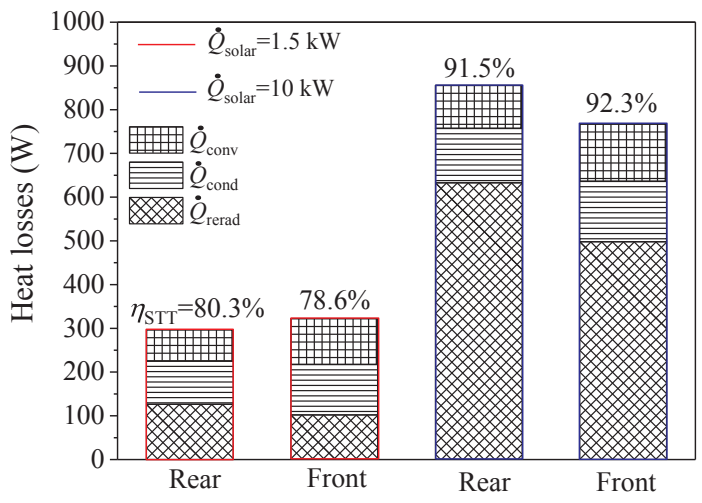

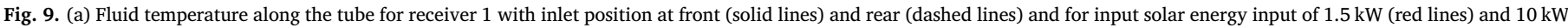

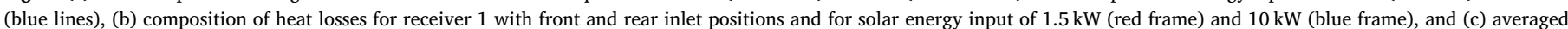

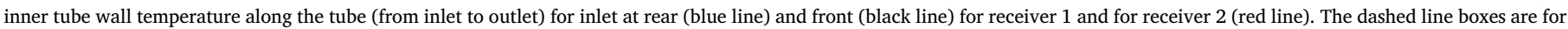
the indication of dryout point. (For interpretation of the references to color in this figure legend, the reader is referred to the web version of this article.)

receiver's performance, however dependent on the solar input power magnitude, i.e. the receiver size.

The hot spots due to the dryout of two-phase can be identified based on the predicted tube surface temperature. The tube surface temperature evaluations along the tube length from the inlet to the outlet for receiver 1 with inlet from the front and rear as well as for receiver 2, both at $=1.5 \mathrm{~kW}$, is shown in Fig. 9c. Receiver 2 showed the highest temperature jump at the dryout point (from $475 \mathrm{~K}$ to $775 \mathrm{~K}$ ) due to the

(a)

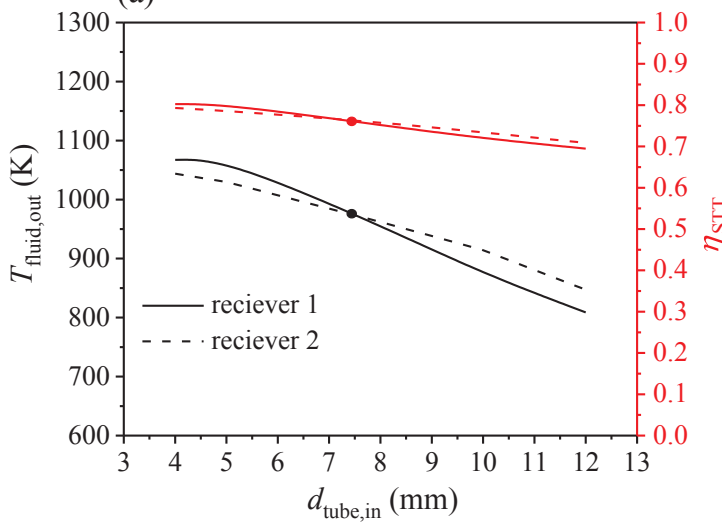

horizontally positioned absorber tubes, leading to lower heat transfer coefficient than the helical tube absorber (which can be treated as a combination of horizontal and vertical tubes). The hot spots due to dryout can be used as an indicator for the critical point where thermomechanical stresses might be high given by the large temperature gradient. In addition to a large temperature jump at the dryout point, receiver 2 showed a wave-like behavior in the tube inner surface temperature for each tube, given by the configuration of the fluid passing (b)

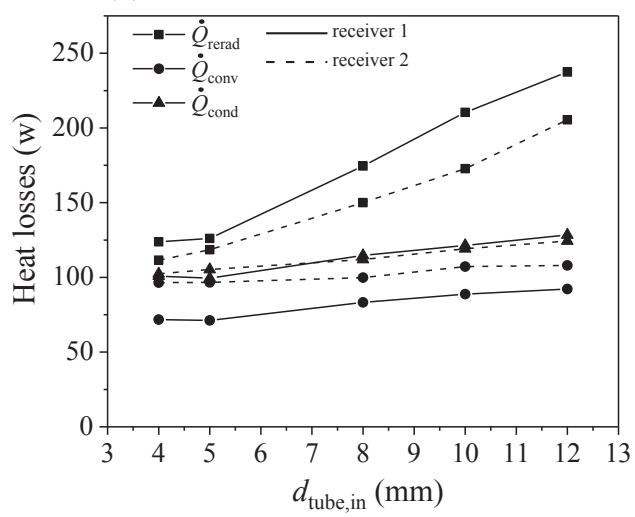

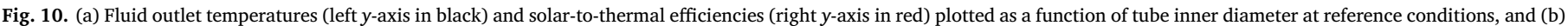

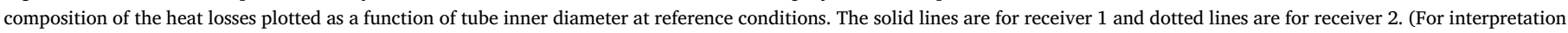
of the references to color in this figure legend, the reader is referred to the web version of this article.) 
through the receiver from rear to front (or front to rear) with a large heat flux difference (Fig. S5 shows the heat flux profile). In contrast, receiver 1 showed smaller temperature variation in both the subcooled region and the superheated region due to smoother heat flux profiles (Fig. S5). The two cases with fluid inlet from the front and from the rear had very similar temperature jumps at the dryout hot spot ( $430 \mathrm{~K}-635 \mathrm{~K}$ for inlet from the rear and $438 \mathrm{~K}-637 \mathrm{~K}$ for inlet from the front). However, the case with the fluid inlet from the front had less stringent temperature gradients in the dryout hot spot superheated region than the case with inlet from rear (see Fig. 9c), which can potentially lead to smaller thermal stresses.

\subsection{Tube diameter}

The effect of different tube diameters, $d_{\text {tube,in, on the receiver }}$ thermal performance were investigated which can be used to guide the choice of optimal tube diameter. The tube inner diameters were varied from $4 \mathrm{~mm}$ to $12 \mathrm{~mm}$, details on the position are indicated in Table S3. We kept the cavity size to be unchanged, resulting in a decrease in the total tube length with increasing tube diameter. In general, the total tube length for receiver 1 and receiver 2 were close (within $8 \mathrm{~cm}$ for most of the cases and is changing due to the use of integer tube numbers only for receiver 2). For receiver 1 and receiver 2, the tubes were placed close to the cavity walls, with $1 \mathrm{~mm}$ distance between the tube wall and cavity wall. This was done in order to avoid direct contact of the absorber tubes with the insulation and benefit from the low thermal conductivity of air. For receiver 2 , the tubes were uniformly arranged inside the cavity with $0.5 \mathrm{~mm}$ distance between two neighboring tubes. In general, receiver 1 and receiver 2 showed decreasing solar-tothermal efficiency with increasing $d_{\text {tube,in }}$, due to reduced absorbing surface area and fluid residence time in the tubes. Receiver 1 showed better solar-to-thermal efficiency than receiver 2 when $d_{\text {tube,in }}$ was smaller than $\sim 7.5 \mathrm{~mm}$ (Fig. 10a). Receiver 1 benefited from lower convective heat losses $\left(\dot{Q}_{\text {conv }}=71.8 \mathrm{~W}\right.$ for receiver 1 and $\dot{Q}_{\text {conv }}=96.5 \mathrm{~W}$ for receiver 2 at $d_{\text {tube, in }}=4 \mathrm{~mm}$ ) at lower tube diameters. At larger $d_{\text {tube, in }}$ (larger than $\sim 7.5 \mathrm{~mm}$ ), the lower convective losses were counteracted by the dominating $\dot{Q}_{\text {rerad }}$, caused by increasing average tube surface temperature at large inner tube diameter (see Fig. 10b), similar as for the emissivity variation investigation (see Section 3.5).

\subsection{Shape of the helical tube}

Two conical shaped helical tubes (shape 1 and shape 2, see Fig. 11) for receiver 1 were investigated with $H_{\text {helical }}$ kept at the reference condition $(0.08 \mathrm{~m})$. For shape 1 , the bottom turning radius was $0.02 \mathrm{~m}$ and the top turning radius was $0.04 \mathrm{~m}$. For shape 2, the top and bottom turning radius was reversed, compared to shape 1 . Compared with shape 1 and shape 2, the reference shape showed larger solar-tothermal efficiency, independent of the magnitude of the solar irradiation input power at the aperture (Fig. 11). For example, shape 1 receiver exhibited a solar-to-thermal efficiency of $79.7 \%$ and shape 2 receiver showed an efficiency of only $73.2 \%$, while the reference shape reached an efficiency of $80.3 \%$, all at reference conditions. Shape 1 showed slightly higher conductive $(76.9 \mathrm{~W}$ for Shape 1 and $71.2 \mathrm{~W}$ for reference shape) and re-radiative (128.9 W for Shape 1 and $126.1 \mathrm{~W}$ for reference shape) heat losses than the reference shape. The significantly lower efficiency of the shape 2 receiver resulted from much higher reradiation losses (292.6 W) compared to the shape 1 and reference shape receivers. This disadvantage in the re-radiation losses was even more significant at larger solar irradiation input power. For example, when $\dot{Q}_{\text {solar }}=10 \mathrm{~kW}$, shape 1 and reference shape receivers reached efficiencies as high as $91.1 \%$ and $91.5 \%$, respectively, while shape 2 reached only $73.4 \%$.

Based on our analysis, it is reasonable to choose the cylindrically shaped helical tube. Receivers with this tube shape achieve high

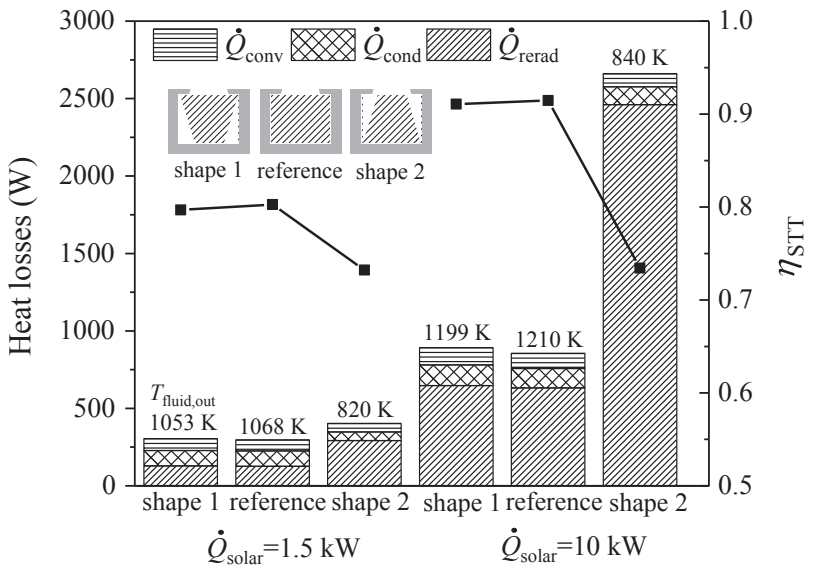

Fig. 11. Heat losses, solar-to-thermal efficiency, and fluid outlet temperature for the three difference shapes of helical tubes (shape 1 , shape 2 , and reference case) and two different solar irradiation energies at the aperture $(1.5 \mathrm{~kW}$ and $10 \mathrm{~kW})$. The different shapes are illustrated in the top left corner. The solid lines with square symbols indicate the solar-tothermal efficiency. The fluid outlet temperatures are shown on top of each bar.

efficiency and are reasonably simple to manufacture.

\subsection{Cooled receiver front}

In a practical implementation of the receiver, a water-cooled receiver front is usually employed to avoid overheating and damage caused by spillage irradiation at the receiver front. To simulate the effect of the water-cooled receiver front, we used a fixed temperature boundary condition at the receiver front surface $\left(T_{\text {front }}=300 \mathrm{~K}\right)$ instead of the mixed convective and radiation boundary (see section 2.1.3). In Fig. 12, we investigated the effect of using a cooled front on the solarto-thermal efficiency at two solar irradiation conditions $(1.5 \mathrm{~kW}$ and $10 \mathrm{~kW}$ ). In general, the utilization of water-cooled receiver fronts leads to an increase in conductive heat losses from the front, decreasing the solar-to-thermal efficiency of the receiver. For example, the conductive heat loss for receiver 1 at $\dot{Q}_{\text {solar }}=1.5 \mathrm{~kW}$ was $99.5 \mathrm{~W}$ and increased to $142.1 \mathrm{~W}$ when a water-cooled front was used. Consequently, a temperature decrease of $33 \mathrm{~K}$ in the fluid outlet temperature was observed and the solar-to-thermal efficiency decreased from $80.3 \%$ to $79.7 \%$ (Fig. 12a). For $\dot{Q}_{\text {solar }}=10 \mathrm{~kW}$, the conductive heat losses increased from $124.7 \mathrm{~W}$ to $203.2 \mathrm{~W}$ leading to $12 \mathrm{~K}$ decrease in the outlet fluid temperature and an $0.4 \%$ decrease in efficiency. This indicates that the increase of the incidence solar irradiance could reduce the negative impact of the water-cooled front on the receiver efficiency. Similar behavior was observed for receiver 2 . The introduction of the cooled front led to a reduced fluid outlet temperature of $9 \mathrm{~K}$ and a reduction in solar-to-thermal efficiency by absolute $0.5 \%$. Similar effects of the cooled front on the thermal performance of receiver 2 was found (Fig. 12b).

The introduction of a water-cooled receiver front, protecting the receiver from spillage irradiation, is accompanied by large heat losses. However, this heat loss becomes less significant when the receiver is scaled.

\section{Conclusions}

A validated numerical model for a solar receiver with indirectly irradiated absorber tubes for the direct steam generation was developed. The model coupled a 3D receiver cavity heat transfer model (accounting for conduction, natural convection, and radiation inside the receiver) with a 1D two-phase flow model (solving for two-phase flow inside the absorber tubes). This generalized numerical frameworks offers an accurate and fast tool for the performance evaluation as well as engineering design for indirectly irradiated tubular solar receiver. 
(a)

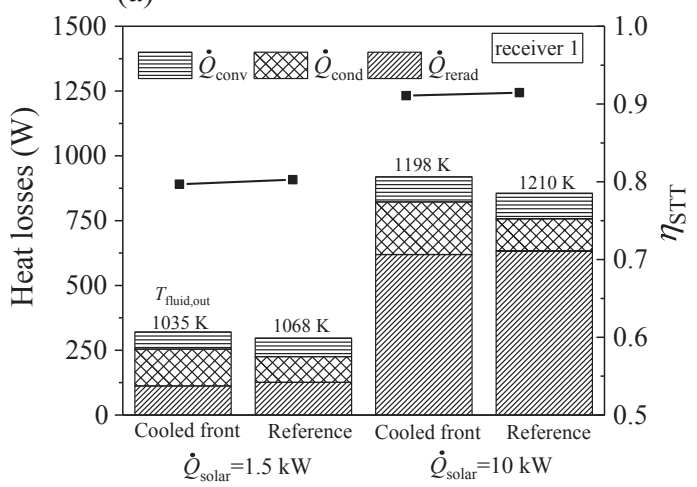

(b)

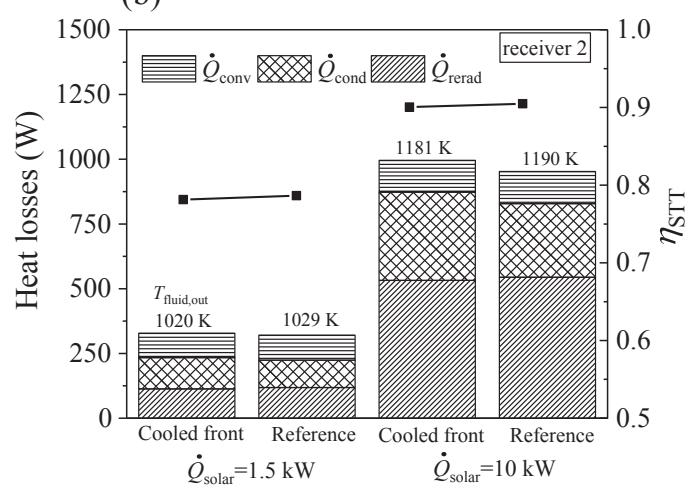

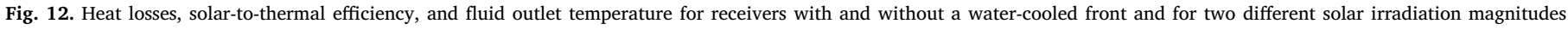

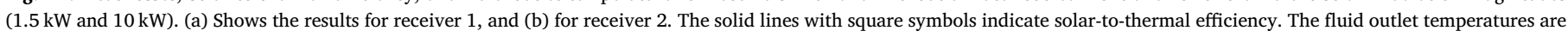
shown on top of each bar.

Particularly, this numerical model can be used to predict performance for the tubular solar receiver for direct stream generation. Two different receiver designs (i.e. receiver 1: with a helical absorber tube, and receiver 2: with straight, connected tubes) were investigated as a function of various operation conditions and receiver designs, i.e. fluid flow rates, pressure, surface emissivity, inlet position, tube diameter, helical shape, and the water-cooled receiver front.

Under reference conditions, receiver 1 exhibited larger re-radiation heat losses and smaller conductive and convective heat losses compared to receiver 2. The solar-to-thermal efficiency was always higher for receiver 1 than receiver 2 due to higher conductive and convective heat losses. This inferiority in solar-to-thermal efficiency for receiver 2 could be alleviated when a larger solar power was applied, resulting from the dominance of re-radiation heat losses.

The flow rate had a significant effect on the solar-to-thermal efficiency and the fluid outlet conditions. In general, the efficiency increased with the increasing flow rate for receiver 1 and this increase reduced when the flow rate was larger than $0.55 \mathrm{~g} / \mathrm{s}$ under reference conditions. Receiver 2 showed an increasing efficiency with flow rate when the flow rate was smaller than $1 \mathrm{~g} / \mathrm{s}$. Further increase in flow rate lead to a light decrease in solar-to-thermal efficiency resulted from increased heat losses.

Receiver 1 was more sensitive to the variation in pressure than receiver 2 . In general, the solar-to-thermal efficiency decreases with increasing inlet fluid pressure. Under reference conditions, there existed a pressure region (10-15 bar) where the decrease in efficiency was more prominent. Higher tube surface emissivity always favored higher solarto-thermal efficiency. Receiver 2 showed larger solar-to-thermal efficiency than receiver 1 when $\varepsilon_{\text {tube }}$ was smaller than 0.58 . This offers a guideline to choose receiver designs and tube materials. Additionally, receiver 2 might be the choice in cases where pressure variations are not well tolerated in downstream applications.

For receiver 1, the fluid inlet position played an important role in determining the solar-to-thermal efficiency of the receiver. When the re-radiation heat loss dominated (at large input solar power, $10 \mathrm{~kW}$ in this study), the rear inlet case showed better performance as the reradiation reduced when cold fluid passed through tube parts close to aperture. The front inlet is recommended in cases where the conductive and convective heat losses dominate (at small input solar power, $1.5 \mathrm{~kW}$ in this study).

Smaller tube diameters always led to higher efficiency of the receivers. Receiver 1 had better efficiency than receiver 2 under reference conditions when the inner tube diameter was smaller than $\sim 7.5 \mathrm{~mm}$. While receiver 2 showed larger efficiency at inner tube diameter larger than $\sim 7.5 \mathrm{~mm}$. This transition resulted from the smaller $\dot{Q}_{\text {rerad }}$ for receiver 2 which dominated the heat losses. The reference shape (cylindrical) of helical tube for receiver 1 exhibited a higher solar-to- thermal efficiency than two conical shapes of the helical tube (shape 1 and shape 2). Shape 1 showed very close performance to the reference case and the difference was further reduced by larger solar power input. A significant reduction in efficiency was found in the case with shape 2 , resulting from very high re-radiation losses which were even more prominent at higher solar power input.

The use of a water-cooled front can protect the receiver front from overheating caused by spillage irradiation. The introduction of a watercooled front led to higher conductive heat losses which, in turn, resulted in lower solar-to-thermal efficiency, in the range of $\sim 0.5-1.5 \%$. This decrease in efficiency could be reduced by going to higher solar power input, favoring scaled-up designs of the receiver.

For the scaled receiver, the inlet flow rate will be significantly larger which will lead to a bypassing or reduction of the stratified flow/stratified-wavy flow while elongating the annular flow region in horizontal tubes (see Fig. 3b as an example). This may lead to further enhancement in the thermal efficiency given by the improved in-tube heat transfer. Consequently, a scale-up of the receiver might generally show enhanced efficiencies.

Here, we report on the development of a comprehensive and computationally-effective solar receiver model with special focus on the modeling of the two-phase flow in the solar-driven direct steam generation systems. We quantified the thermal efficiency and each heat loss mechanism for two types of tubular receivers under various operational conditions, material properties, and tube geometries. Our investigation showed that receiver designs achieving high performance in the direct steam generation are possible when carefully considering tube types (multiple tubes and helical tube), surface emissivity, fluid inlet position, target operation temperature, flow rates, and incoming solar power which offers practical design guidelines for direct steam generation solar receiver.

\section{Acknowledgments}

The research leading to these results has received funding from the European Union's Seventh Framework Programme (FP7/2007-2013) for the Fuel Cells and Hydrogen Joint Technology Initiative under grant agreement $n^{\circ} 621173$ (project SOPHIA). We thank the Chinese Scholarship Council for partial financial support of the doctoral studies of Meng Lin. We thank Roman Bader for fruitful discussions on natural convection modeling.

\section{Appendix A. Supplementary material}

Supplementary data associated with this article can be found, in the online version, at http://dx.doi.org/10.1016/j.apenergy.2018.02.044. 


\section{References}

[1] Zhang HL, Baeyens J, Degrève J, Cacères G. Concentrated solar power plants: review and design methodology. Renew Sustain Energy Rev 2013;22:466-81. http:// dx.doi.org/10.1016/j.rser.2013.01.032.

[2] Lovegrove K, Burgess G, Pye J. A new $500 \mathrm{~m}^{2}$ paraboloidal dish solar concentrator. Sol Energy 2011;85:620-6. http://dx.doi.org/10.1016/j.solener.2010.01.009.

[3] Zarza E, Valenzuela L, León J, Hennecke K, Eck M, Weyers HD, et al. Direct steam generation in parabolic troughs: final results and conclusions of the DISS project. Energy 2004;29:635-44. http://dx.doi.org/10.1016/S0360-5442(03)00172-5.

[4] Buck R, Bräuning T, Denk T, Pfänder M, Schwarzbözl P, Tellez F. Solar-hybrid gas turbine-based power tower systems (REFOS). J Sol Energy Eng 2002;124:2. http:// dx.doi.org/10.1115/1.1445444.

[5] Bader R, Pedretti A, Barbato M, Steinfeld A. An air-based corrugated cavity-receiver for solar parabolic trough concentrators. Appl Energy 2015;138:337-45. http://dx. doi.org/10.1016/j.apenergy.2014.10.050.

[6] Kodama T, Gokon N. Thermochemical cycles for high-temperature solar hydrogen production. Chem Rev 2007;107:4048-77.

[7] Chueh WC, Falter C, Abbott M, Scipio D, Furler P, Haile SM, et al. High-flux solardriven thermochemical dissociation of $\mathrm{CO}_{2}$ and $\mathrm{H}_{2} \mathrm{O}$ using nonstoichiometric ceria. Science 2010;330:1797-801. http://dx.doi.org/10.1126/science.1197834.

[8] Bader R, Venstrom LJ, Davidson JH, Lipiński W. Thermodynamic analysis of isothermal redox cycling of ceria for solar fuel production. Energy Fuels 2013;27:5533-44. http://dx.doi.org/10.1021/ef400132d.

[9] Lin M, Haussener S. Solar fuel processing efficiency for ceria redox cycling using alternative oxygen partial pressure reduction methods. Energy 2015;88:667-79. http://dx.doi.org/10.1016/j.energy.2015.06.006.

[10] Davenport TC, Yang CK, Kucharczyk CJ, Ignatowich MJ, Haile SM. Maximizing fuel production rates in isothermal solar thermochemical fuel production. Appl Energy 2016;183:1098-111. http://dx.doi.org/10.1016/j.apenergy.2016.09.012.

[11] Sanz-Bermejo J, Muñoz-Antón J, Gonzalez-Aguilar J, Romero M. Optimal integration of a solid-oxide electrolyser cell into a direct steam generation solar tower plant for zero-emission hydrogen production. Appl Energy 2014;131:238-47. http://dx. doi.org/10.1016/j.apenergy.2014.06.028.

[12] Bala Chandran R, De Smith RM, Davidson JH, Chandran RB, De Smith RM, Davidson JH. Model of an integrated solar thermochemical reactor/reticulated ceramic foam heat exchanger for gas-phase heat recovery. Int J Heat Mass Transf 2015;81:404-14. http://dx.doi.org/10.1016/j.ijheatmasstransfer.2014.10.053.

[13] Haussener S, Hirsch D, Perkins C, Weimer a, Lewandowski a, Steinfeld a. Modeling of a multitube high-temperature solar thermochemical reactor for hydrogen production. J Sol Energy Eng 2009;131:24503. http://dx.doi.org/10.1115/1.3097280.

[14] Melchior T, Perkins C, Weimer AW, Steinfeld A. A cavity-receiver containing a tubular absorber for high-temperature thermochemical processing using concentrated solar energy. Int J Therm Sci 2008;47:1496-503. http://dx.doi.org/10. 1016/j.ijthermalsci.2007.12.003.

[15] Melchior T, Steinfeld A. Radiative transfer within a cylindrical cavity with diffusely/specularly reflecting inner walls containing an array of tubular absorbers. J Sol Energy Eng 2008;130:21013. http://dx.doi.org/10.1115/1.2888755.

[16] Martinek J, Bingham C, Weimer AW. Computational modeling and on-sun model validation for a multiple tube solar reactor with specularly reflective cavity walls Part 1: Heat transfer model. Chem Eng Sci 2012;81:298-310. http://dx.doi.org/10. 1016/j.ces.2012.06.064

[17] Prakash M, Kedare SB, Nayak JK. Investigations on heat losses from a solar cavity receiver. Sol Energy 2009;83:157-70. http://dx.doi.org/10.1016/j.solener.2008. 07.011 .

[18] Roldán MI, Valenzuela L, Zarza E. Thermal analysis of solar receiver pipes with superheated steam. Appl Energy 2013;103:73-84. http://dx.doi.org/10.1016/j. apenergy.2012.10.021.

[19] Edge PJ, Heggs PJ, Pourkashanian M, Williams A. An integrated computational fluid dynamics-process model of natural circulation steam generation in a coal-fired power plant. Comput Chem Eng 2011;35:2618-31. http://dx.doi.org/10.1016/j. compchemeng.2011.04.003.

[20] Sunil PU, Barve J, Nataraj PSV. Mathematical modeling, simulation and validation of a boiler drum: Some investigations. Energy 2017;126:312-25. http://dx.doi.org/ 10.1016/j.energy.2017.02.140.

[21] Jo JC, Kim WS, Choi C-Y, Lee YK. Numerical simulation of subcooled flow boiling heat transfer in helical tubes. J Press Vessel Technol 2009;131:11305. http://dx. doi.org/10.1115/1.3028022.

[22] Tentner A, Merzari E, Vegendla P. Computational fluid dynamics modeling of twophase boiling flow and critical heat flux. 2014 22nd Int. Conf. Nucl. Eng.. American Society of Mechanical Engineers; 2014. p. V004T10A037-V004T10A037.

[23] Li H, Huang X, Zhang L. A lumped parameter dynamic model of the helical coiled once-through steam generator with movable boundaries. Nucl Eng Des 2008;238:1657-63. http://dx.doi.org/10.1016/j.nucengdes.2008.01.009.

[24] Oliet C, Pérez-Segarra CD, Castro J, Oliva a. Modelling of fin-and-tube evaporators considering non-uniform in-tube heat transfer. Int J Therm Sci 2010;49:692-701. http://dx.doi.org/10.1016/j.ijthermalsci.2009.11.009.

[25] Sinpiboon J, Wongwises S. Numerical investigation of refrigerant flow through nonadiabatic capillary tubes. Appl Therm Eng 2002;22:2015-32. http://dx.doi.org/10. 1016/S1359-4311(02)00129-1.

[26] Dhir VK. Mechanistic prediction of nucleate boiling heat transfer-achievable or a hopeless task? J Heat Transfer 2006;128:1. http://dx.doi.org/10.1115/1.2136366.

[27] Son G, Dhir VK, Ramanujapu N. Dynamics and heat transfer associated with a single bubble during nucleate boiling on a horizontal surface. J Heat Transfer 1999;121:623-31.
[28] Das S, Punekar H. On development of a semi-mechanistic wall boiling model, ASME 2013 Int. Mech. Eng. Congr. Expo. V08BT09A075-V08BT09A075; 2013. 10.1115/ IMECE2013-66179.

[29] Abishek S, King AJC, Narayanaswamy R. Computational analysis of two-phase flow and heat transfer in parallel and counter flow double-pipe evaporators. Int J Heat Mass Transf 2017;104:615-26. http://dx.doi.org/10.1016/j.ijheatmasstransfer. 2016.08.089.

[30] Krepper E, Končar B, Egorov Y. CFD modelling of subcooled boiling—concept, validation and application to fuel assembly design. Nucl Eng Des 2007;237:716-31. http://dx.doi.org/10.1016/j.nucengdes.2006.10.023.

[31] Li H, Vasquez SA, Punekar H, Muralikrishnan R. Prediction of boiling and critical heat flux using an eulerian multiphase boiling model. Fluids Therm Syst Adv Process Ind Parts A B 2011;vol. 6:463-76. http://dx.doi.org/10.1115/IMECE201165539.

[32] Celata GP, Mishima K, Zummo G. Critical heat flux prediction for saturated flow boiling of water in vertical tubes. Int J Heat Mass Transf 2001;44:4323-31. http:// dx.doi.org/10.1016/S0017-9310(01)00072-2.

[33] Lifante C, Frank T, Burns A. Wall boiling modeling extension towards critical heat flux; n.d.

[34] Kurul N, Podowski MZ. On the modeling of multidimensional effects in boiling channels. In: 27th Natl heat transf conf; 1991. p. 21-6.

[35] Thome JR. Engineering data book III, Wolver. Tube Inc. 2010; 2004.

[36] Liu Z, Winterton RHS. A general correlation for saturated and subcooled flow boiling in tubes and annuli, based on a nucleate pool boiling equation. Int $\mathrm{J}$ Heat Mass Transf 1991;34:2759-66. http://dx.doi.org/10.1016/0017-9310(91)90234-6.

[37] Cheng L, Ribatski G, Thome JR. Two-phase flow patterns and flow-pattern maps: fundamentals and applications. Appl Mech Rev 2008;61:50802. http://dx.doi.org/ 10.1115/1.2955990.

[38] Roth GA, Aydogan F. Theory and implementation of nuclear safety system codes Part II: System code closure relations, validation, and limitations. Prog Nucl Energy 2014;76:55-72. http://dx.doi.org/10.1016/j.pnucene.2014.05.003.

[39] Escanes F, Pérez-Segarra CD, Oliva a. Numerical simulation of capillary-tube expansion devices. Int J Refrig 1995;18:113-22. http://dx.doi.org/10.1016/01407007(95)93894-P.

[40] García-Valladares O, Pérez-Segarra CD, Oliva A. Numerical simulation of capillary tube expansion devices behaviour with pure and mixed refrigerants considering metastable region. Part I: Mathematical formulation and numerical model. Appl Therm Eng 2002;22:173-82. http://dx.doi.org/10.1016/S1359-4311(01)00074-6.

[41] Colorado D, Hernández Ja, García-Valladares O, Huicochea a, Siqueiros J. Numerical simulation and experimental validation of a helical double-pipe vertical condenser. Appl Energy 2011;88:2136-45. http://dx.doi.org/10.1016/j.apenergy. 2010.12.026.

[42] Kattan N, Thome JR, Favrat D. Flow boiling in horizontal tubes: Part 1-Development of a diabatic two-phase flow pattern map. J Heat Transfer 1998;120:140-7. http://dx.doi.org/10.1115/1.2830037.

[43] Martinek J, Ma Z. Granular flow and heat transfer study in a near-blackbody en closed particle receiver. ASME 2014 8th int conf energy sustain. Collocated with ASME 2014 12th Int Conf Fuel Cell Sci Eng Technol. American Society of Mechanical Engineers; 2014. p. V001T02A012-V001T02A012.

[44] Martinek J, Bingham C, Weimer AW. Computational modeling of a multiple tube solar reactor with specularly reflective cavity walls. Part 2: Steam gasification of carbon. Chem Eng Sci 2012;81:285-97. http://dx.doi.org/10.1016/j.ces.2012.06. 065.

[45] Haussener S, Thomey D, Roeb M, Steinfeld A. Multi-scale modelling of a solar reactor for the high-temperature step of a sulphur-iodine-based water splitting cycle. ASME 2012 heat transf summer conf collocated with ASME 2012 fluids eng div summer meet ASME 2012 10th int conf nanochannels, microchannels, minichannels. American Society of Mechanical Engineers; 2012. p. 287-96.

[46] Reddy KS, Vikram TS, Veershetty G. Combined heat loss analysis of solar parabolic dish - modified cavity receiver for superheated steam generation. Sol Energy 2015. http://dx.doi.org/10.1016/j.solener.2015.04.028.

[47] Zhu J, Wang K, Wu H, Wang D, Du J, Olabi AG. Experimental investigation on the energy and exergy performance of a coiled tube solar receiver. Appl Energy 2015;156:519-27. http://dx.doi.org/10.1016/j.apenergy.2015.07.013.

[48] Zapata JI, Asselineau C-A, Pye J, Kaufer M, Hughes G. An integrated optical and thermal model of cavity receivers for paraboloidal dish concentrators; n.d.

[49] Wang P, Liu DY, Xu C. Numerical study of heat transfer enhancement in the receiver tube of direct steam generation with parabolic trough by inserting metal foams. Appl Energy 2013;102:449-60. http://dx.doi.org/10.1016/j.apenergy.2012.07. 026 .

[50] Faghri A, Zhang Y. Transport phenomena in multiphase systems. Academic Press; 2006.

[51] Steinfeld a, Schubnell M. Optimum aperture size and operating temperature of a solar cavity-receiver. Sol Energy 1993;50:19-25. http://dx.doi.org/10.1016/0038092X(93)90004-8.

[52] Paitoonsurikarn S, Lovegrove K. Numerical investigation of natural convection loss in cavity-type solar receivers in solar dish applications, Sol. 2002-Austrailian New Zeal. Sol Energy Soc 2002;133:6. http://dx.doi.org/10.1115/1.4003582.

[53] Lienhard JH. A heat transfer textbook. Courier Corporation; 2013.

[54] Leibfried U, Ortjohann J. Convective Heat loss from upward and downward-facing cavity solar receivers: measurements and calculations. J Sol Energy Eng 1995;117:75. http://dx.doi.org/10.1115/1.2870873.

[55] Hischier I, Hess D, Lipinski W, Modest M, Steinfeld A. Heat transfer analysis of a novel pressurized air receiver for concentrated solar power via combined cycles. $\mathrm{J}$ Therm Sci Eng Appl 2009;1:41002. http://dx.doi.org/10.1115/1.4001259.

[56] Friedel L. Improved friction pressure drop correlations for horizontal and vertical 
two-phase pipe flow. In: Eur two-phase flow gr meet Pap E; 1979. p. 1979.

[57] Bell IH, Wronski J, Quoilin S, Lemort V. Pure and pseudo-pure fluid thermophysical property evaluation and the open-source thermophysical property library CoolProp. Ind Eng Chem Res 2014;53:2498-508.

[58] Steiner D. Heat Transfer to Boiling Saturated Liquids (VDI-Wärmeatlas), VDI Heat Atlas. VDI-Gessellschaft Verfahrenstechnik Und Chemieinge Nieurwes. (GCV), Düsseldorf, Ger. (JW Fullarton, Transl; 1993.

[59] Rouhani SZ, Axelsson E. Calculation of void volume fraction in the subcooled and quality boiling regions. Int J Heat Mass Transf 1970;13:383-93. http://dx.doi.org/ 10.1016/0017-9310(70)90114-6.

[60] Woldesemayat Ma, Ghajar AJ. Comparison of void fraction correlations for different flow patterns in horizontal and upward inclined pipes. Int J Multiph Flow 2007;33:347-70. http://dx.doi.org/10.1016/j.ijmultiphaseflow.2006.09.004.

[61] Thome JR, El Hajal J. Two-phase flow pattern map for evaporation in horizontal tubes: latest version. Heat Transf Eng 2003;24:3-10.

[62] Taitel Y, Dukler AE. A model for predicting flow regime transitions in horizontal and near horizontal gas-liquid flow. AIChE J 1976;22:47-55. http://dx.doi.org/10. 1002/aic.690220105.

[63] Elsafi AM. On thermo-hydraulic modeling of direct steam generation. Sol Energy 2015;120:636-50. http://dx.doi.org/10.1016/j.solener.2015.08.008.

[64] Cooper MG. Heat flow rates in saturated nucleate pool boiling - a wide- ranging examination using reduced properties. Adv Heat Transf 1984;16:157-239. http:/
dx.doi.org/10.1017/CBO9781107415324.004.

[65] Groeneveld DC. Post-dryout heat transfer at reactor operating conditions. Chalk River, Ont.: Atomic Energy of Canada Limited; 1973.

[66] Biberg D. Explicit approximation for the wetted angle in two-phase stratified pipe flow. Can J Chem Eng 1999;77:1221-4. http://dx.doi.org/10.1002/cjce. 5450770619.

[67] Dittus FW, Boelter LMK. Heat transfer in automobile radiators of the tubular type. Int Commun Heat Mass Transf 1985;12:3-22.

[68] Thome JR. Flow boiling in horizontal tubes: Part 3-Development of a new heat transfer model based on flow pattern. J Heat Transfer 1998;120:156-65.

[69] VDI-Gesellschaft, VDI Heat Atlas; 2015. 10.1017/CBO9781107415324.004.

[70] Gungor KE, Winterton RHS. A general correlation for flow boiling in tubes and annuli. Int J Heat Mass Transf 1986;29:351-8. http://dx.doi.org/10.1016/00179310(86)90205-X.

[71] Kakaç S, Shah RK, Aung W. Handbook of single-phase convective heat transfer. New York: Wiley; 1987. et al.

[72] Gupta R, Wanchoo RK, Jafar TRM. Ali, Laminar flow in helical coils: a parametric study. Ind Eng Chem Res 2011:1150-7. http://dx.doi.org/10.1021/ie101752z.

[73] Fluent A. Ansys fluent. Acad Res Release, vol. 17(2); 2016.

[74] Lobón DH, Baglietto E, Valenzuela L, Zarza E. Modeling direct steam generation in solar collectors with multiphase CFD. Appl Energy 2014;113:1338-48. http://dx. doi.org/10.1016/j.apenergy.2013.08.046. 